NBER WORKING PAPER SERIES

\title{
SHOPPING FOR LOWER SALES TAX RATES
}

\author{
Scott R. Baker \\ Stephanie Johnson \\ Lorenz Kueng \\ Working Paper 23665 \\ http://www.nber.org/papers/w23665 \\ NATIONAL BUREAU OF ECONOMIC RESEARCH \\ 1050 Massachusetts Avenue \\ Cambridge, MA 02138 \\ August 2017, Revised May 2018
}

We would like to thank our discussants Gabe Chodorow-Reich, Jonathan Parker and Inessa Liskovich, and participants at seminars at the NBER Summer Institute, Arizona State, Berkeley, Bern, Chicago Fed, Columbia, Frankfurt, Minneapolis Fed, Minnesota, Munich, Northwestern, NYU, Venice, Wisconsin\{Madison, and Yale for their comments. This research received financial support from the Alfred P. Sloan Foundation through the NBER Household Finance small grant program and from the Financial Institutions and Markets Research Center at the Kellogg School of Management. Conclusions in this paper are derived based on data from The Nielsen Company (US), LLC and marketing databases provided by the Kilts Center for Marketing Data Center at The University of Chicago Booth School of Business. The conclusions drawn from the Nielsen data are those of the researchers and do not reflect the views of Nielsen. Nielsen is not responsible for, had no role in, and was not involved in analyzing and preparing the results reported herein. The views expressed herein are those of the authors and do not necessarily reflect the views of the National Bureau of Economic Research.

NBER working papers are circulated for discussion and comment purposes. They have not been peer-reviewed or been subject to the review by the NBER Board of Directors that accompanies official NBER publications.

(C) 2017 The Nielsen Company (US), LLC. Circulated with permission. All rights reserved. Short sections of text, not to exceed two paragraphs, may be quoted without explicit permission provided that full credit, including (C) notice, is given to the source. 
Shopping for Lower Sales Tax Rates

Scott R. Baker, Stephanie Johnson, and Lorenz Kueng

NBER Working Paper No. 23665

August 2017, Revised May 2018

JEL No. D12,E21,H31

\begin{abstract}
Using comprehensive high-frequency state and local sales tax data, we show that shopping behavior responds strongly to changes in sales tax rates. Even though sales taxes are not observed in posted prices and have a wide range of rates and exemptions, consumers adjust in many dimensions. They stock up on storable goods before taxes rise and increase online and crossborder shopping in both the short and long run. The differences between short- and long-run spending responses have important implications for the efficacy of using sales taxes for countercyclical policy and for the design of an optimal tax framework. Interestingly, households adjust spending similarly for both taxable and tax-exempt goods. We embed an inventory problem into a continuous-time consumption-savings model and demonstrate that this seemingly irrational behavior is optimal in the presence of shopping trip fixed costs. The model successfully matches estimated short-run and long-run tax elasticities with an implied after-tax reservation wage of \$7-10. We provide additional evidence in favor of this new shopping-complementarity mechanism.

Scott R. Baker

Northwestern University Kellogg

School of Management Suite 4394

2211 Campus Drive

Evanston, IL 60208

s-baker@kellogg.northwestern.edu

Stephanie Johnson

Northwestern University

Department of Economics

2211 Campus Drive

Evanston, IL 60208

stephgwallace@gmail.com

Lorenz Kueng

Northwestern University

Kellogg School of Management

Suite 4394

2211 Campus Drive

Evanston, IL 60208

and NBER

1-kueng@kellogg.northwestern.edu
\end{abstract}




\section{Introduction}

Quantifying the extent to which households respond to sales tax rates is important for both macroeconomics and public finance. These estimates, for both short-run and long-run responses, are crucial for tax incidence, optimal taxation, and the effectiveness of macroeconomic policies.

Recent empirical work has investigated the nation-wide responses of consumer spending to changes in value-added taxes (VAT) in several countries (Crossley, Low and Sleeman (2014), Cashin and Unayama (2016), D'Acunto, Hoang and Weber (2017)). However, due to differences in the implementation of sales taxes, these international estimates may not translate well into predicted household responses in a US context. ${ }^{1}$ In fact, a range of recent studies has found empirical evidence of substantial deviations from frictionless optimizing behavior in such situations where taxes and fees are often complex or partially hidden, as sales taxes are in the US (Chetty, Looney and Kroft (2009), Finkelstein (2009), Cabral and Hoxby (2013)). ${ }^{2}$

Consumption taxes have also received renewed attention in the aftermath of the financial crisis as an alternative policy tool to stimulate aggregate demand during a liquidity trap when monetary policy is constrained by the "zero lower bound" on nominal interest rates (Correia, Farhi, Nicolini and Teles, 2013). ${ }^{3}$ However, inattention to sales tax rates could reduce the effectiveness of sales tax changes (and similar small or temporary tax policies) as a macroeconomic policy (Gabaix, 2016), while increasing the efficiency of the revenue-raising aspects of the tax through a reduction in consumption distortion (Farhi and Gabaix, 2017).

This paper makes two main contributions to this literature. First, we undertake the most comprehensive analysis of consumer responses to sales tax rate changes in the US to better inform this discussion. ${ }^{4}$ We leverage household-level spending data and 50 state and more than 2,000

\footnotetext{
${ }^{1}$ For instance, while VATs are almost universally included in posted prices, sales taxes in the US are generally not included in prices and are only applied at checkout, making it difficult for consumers to take sales taxes into account when purchasing goods. Moreover, some goods are exempt from taxation, with different states applying different exemption rules. Furthermore, a wide range of overlapping tax jurisdictions can impose their own sales taxes due to the strong fiscal federalism in the U.S., leading to a broad range of tax rates across geographic locations down to the ZIP code level.

${ }^{2}$ There are also important studies that analyze these issues in laboratory experiments; see e.g., Chen, Kaiser and Rickard (2014) and Feldman and Ruffle (2015).

${ }^{3}$ Notably, Agarwal, Marwell and McGranahan (2017) investigate how temporary seasonal sales tax holidays (STH) affect purchasing behavior and note significant responsiveness to these sales. However, STH differ from the sales tax changes used in this paper in important ways. The two tax changes have very different persistence. The average sales tax change lasts about 6 years, while the average STH lasts only 5 days. Moreover, sales tax changes have a much broader tax base, while STH target a narrow range of products. Therefore, sales taxes have a much larger impact on government budgets and are the primary source of tax revenue of local governments. These characteristics may drive differences in both the channels available for households to avoid taxes and differences in consumer attentiveness (since STH occur more regularly and might thus be more salient). For instance, we find strong evidence of intertemporal substitution of spending and spillover on exempt goods, while Agarwal et al. (2017) report that spending on goods covered by STH does not decline before or after the holidays, and there appears no spillover effect on other non-covered goods.

${ }^{4}$ Despite a large amount of interest in and previous work on the impacts of sales taxes, we see our paper as adding significant depth to this literature. Due to generally less comprehensive data, much of the previous literature has focused on elasticities of individual goods like cigarettes or gasoline (e.g., Walsh and Jones (1988), Goolsbee, Lovenheim and Slemrod (2010), DeCicca, Kenkel and Liu (2013)), has been limited to analysis only in the cross-section or at geographically aggregated levels (e.g., Agrawal (2015), Davis, Knoepfle, Sun and Yannelis
} 
distinct local sales tax changes to quantify the elasticity of both taxable and tax-exempt spending with respect to sales tax changes. ${ }^{5}$ We demonstrate that households respond to these changes in both the short and long run, but through different channels. In the short run, spending responses are dominated by intertemporal substitution, while long-run responses to changes in sales taxes are driven by shifts in spending towards online purchases and lower tax jurisdictions. These long-run responses indicate a persistent awareness of the changes in relative prices induced by sales tax changes, despite the fact that they are not explicitly included in posted prices. ${ }^{6}$

Our second contribution is a novel, parsimoniously parametrized model that is consistent with the observed household behavior. The model serves several purposes. First, it endogenizes the response of households at a shopping trip level (in addition to the spending responses). This is important because household transactions in our data are time-stamped, allowing us to estimate this adjustment margin, which disciplines the model in a novel way. Second, the theoretical analysis shows that a model with full attention, calibrated with standard preference parameter values, can simultaneously match all important tax elasticities (the elasticities of shopping trip frequency and of taxable and exempt spending), both in the short and long run. This is important because models with limited attention have similar qualitative predictions and often only differ in the magnitude of the responses. ${ }^{7}$ Third, the model relates the short- and longrun spending responses to the recent literature in public finance and macroeconomics mentioned above. Business-cycle macroeconomics is interested in the short-run spending response, because the effect of counter-cyclical policies depends on the response of aggregate demand (e.g., Mian and Sufi (2012)). ${ }^{8}$ Efficiency cost, static tax incidence, and optimal tax formulas on the other hand depend on long-run consumption elasticities.

Our analysis shows that sales taxes can be both an efficient form of tax revenue in the long run and an effective tool to stimulate the economy in the sort run. The reason is simple. A pre-announced sales tax increase is stimulative in the short run because consumers pay attention to the upcoming tax increase, shifting spending forward from future periods. ${ }^{9}$ At the same time, this form of intertemporal tax arbitrage is short-lived, because households are reluctant to shift

(2016)) or has touched upon only a single channel of sales tax avoidance (e.g., effects on online spending in Goolsbee (2000), Einav, Knoepfle, Levin and Sundaresan (2014), and Baugh, Ben-David and Park (2015)).

${ }^{5}$ The majority of local sales tax changes are at the level of the city.

${ }^{6}$ These significant long-run responses in cross-border and online shopping by households who have the opportunity to do so demonstrate that the small average long-run spending response is due to the fact that (i) intertemporal substitution of spending is limited because consumer goods depreciate and because most consumers are reluctant to substitute between exempt and taxable goods, (ii) most consumers cannot cross easily cross into a lower tax jurisdiction, and (iii) many products cannot easily be purchased online (at least during our sample period). This observation is important since it shows that the low average long-run response is not due to consumers forgetting about sales tax rates over time (e.g., Agarwal, Driscoll, Gabaix and Laibson (2013)).

${ }^{7}$ We thank Xavier Gabaix for pointing out to us that the predictions of a rational model and one with limited attention often differ only in the magnitude of the responses (Gabaix, 2014), and for encouraging us to develop a rational benchmark model.

${ }^{8}$ Previous research has mostly focused on durable demand, while most of the goods in our data are storable and NIPA would classify them as non-durable. We discuss this and related issues in Section 8.

${ }^{9}$ Negative income and wealth effects when announcing the policy could be neutralized either over the business cycle or by offsetting changes to labor income or capital taxation as in Correia et al. (2013). 
consumption intertemporally and between taxable and exempt goods, and because the effect of other long-run avoidance channels such as cross-border and online shopping is quantitatively small. Hence, it is the limited tax avoidance in the long run - not the non-salience of sales taxes - which makes the tax relatively efficient. To highlight this mechanism, we derive closed-form solutions of all important short- and long-run tax elasticities in terms of the structural parameters of the model, which also provides a transparent mapping between the model and the estimated reduced-form tax elasticities.

We account for concerns about the endogeneity of sales tax changes by leveraging the high frequency panel nature of the data and the long fiscal lag between the announcement of the tax change and its implementation. ${ }^{10}$ From the time when an upcoming sales tax change is made public, it will typically take 6-12 months before the change is put into practice. This makes it less likely that a sales tax change will occur contemporaneously with a significant local economic shock. In addition, we note both a significant positive spending response in the months before a sales tax increase which is mirrored by a decline after the increase in rates. This sharp spending reversal is unlikely to be caused by a monotonic trend in local economic conditions. Finally, we can take advantage of the substantial number of tax changes in our sample to include time fixed effects, accounting for seasonal and business-cycle patterns. Consistent with this identification assumption, controlling for local economic conditions does not change the estimated responses.

Using newspaper article counts surrounding sales tax changes, we estimate that the average fiscal lag, the time between tax announcements and implementation, is approximately 6-12 months. Using Google search results, we then show that there is a large and significant spike in searches about sales taxes preceding the sales tax changes, showing that users are using this avenue to find out about upcoming taxes.

We use high-frequency scanner data to show that consumers also act on this information. We find large short-run spending responses to sales tax increases, but smaller spending effects in the long run. ${ }^{11}$ These responses are driven by temporary stockpiling of storable and durable goods. Consumers anticipate an upcoming tax increase and bring spending forward to periods with low tax rates, and this form of intertemporal tax arbitrage is more pronounced for more storable and durable goods. In the long run, intertemporal substitution of spending is no longer an option for households (who appear reluctant to substitute consumption intertemporally and across taxable and exempt goods), though they continue to substitute spending towards lower taxes where possible, through online and cross-border shopping. ${ }^{12}$

\footnotetext{
${ }^{10}$ See Nakamura and Steinsson $(2017,2018)$ and the literature cited therein for a discussion of similar identification approaches in macroeconomics based on high-frequency data.

${ }^{11}$ These responses reflect mostly (compensated) substitution effects if consumers are rational and taxes are salient, because wealth and income effects occur when consumers learn about the upcoming tax changes, which for forward-looking consumers happens before the taxes change. Moreover, since the majority of observed changes are tax increases, credit constraints cannot account for the large short-run spending responses, which are more than twice as large as predicted by hand-to-mouth behavior.

${ }^{12}$ We note that these estimates represent the average response across all households, where some individual households may fail to recognize that taxes have changed or fail to act on the information. Moreover, other households may 'overreact' to the tax news relative to news of an upcoming price change. In this sense, the
} 
To assess whether a model with rational, forward-looking consumers with full attention to sales taxes can match the observed responses, we embed an inventory problem with shopping fixed costs into a standard continuous-time consumption-savings model. Households choose an optimal consumption plan and support this plan by managing inventories of two storable consumer goods, a taxable and a tax-exempt good. Optimal inventories trade off holding costs (e.g., depreciation, opportunity costs) against the two main benefits from holding inventories of storable consumer goods identified by Keynes (1936, chp. 13). ${ }^{13}$ First, consumers can shift purchases to periods with low taxes and prices while keeping consumption smooth. Keynes calls this the speculative motive. Second, consumers can reduce shopping fixed costs by holding larger inventories (e.g., fewer store visits per month), which he calls the transaction motive of inventory demand. We use transaction time stamps to quantify this channel. Consistent with the transaction motive we find that consumers decrease the number of store visits temporarily in the month after a sales tax increase.

Interestingly, we find very similar spending responses for both taxable and tax-exempt goods. While this behavior seems irrational at first, it is perfectly consistent with optimal inventory management. In fact, this is precisely what one would expect under optimal inventory management with shopping fixed costs due to the transaction motive! While shopping for taxable goods when tax rates are still low, consumers can reduce the need for future trips by also stocking up on tax-exempt goods, a mechanism that is only observable with a model that incorporates shopping trips and not simply household spending.

The model highlights that the observed complementarity of taxable and tax-exempt spending is driven by the shared shopping fixed costs, instead of consumption complementarity. We therefore call this property of demand shopping complementarity, because it holds even when the goods are consumption substitutes (which they necessarily are in our two-good model). Moreover, because of these fixed costs, consumers shop infrequently even though they consume continuously. Hence, the model jointly determines the observed reduced-form tax responses of taxable and tax-exempt spending (both short- and long-run) and of shopping trips.

The model is successful in matching the estimated short- and long-run reduced-form tax elasticities using only a few structural parameters. It highlights the stark differences between the elasticities of intertemporal substitution of spending (EIS-S) and consumption (EIS-C) when goods are storable, showing that a high EIS-S is consistent with a low EIS-C, an point forcefully made by Ogaki and Reinhart (1998) and Fernández-Villaverde and Krueger (2001). ${ }^{14}$

\footnotetext{
knowledge or salience of the tax change must certainly have an impact on the overall response. In Appendix C, we discuss some results consistent with this interpretation. In addition, our estimates do not directly address cross-sectional heterogeneity in responses. We test for heterogeneous effects, finding some evidence that higher income households tend to have somewhat larger responses (consistent with a role of liquidity in enabling the stockpiling of goods), but few household characteristics predict differential responses.

${ }^{13}$ Keynes identifies a third motive - precautionary demand - in settings with unanticipated price or consumption shocks. See Hendel and Nevo (2006a) for a modern treatment of this idea using scanner data.

${ }^{14} \mathrm{~A}$ recent literature in industrial organization (IO) also focuses on demand dynamics. In a series of papers, Hendel and Nevo (2006a,b, 2013) show that accounting for consumer inventories is crucial when analyzing demand responses to temporary price reductions, i.e., "sales" (see also the related literature discussed in Coglianese, Davis,
} 
We assess the model's performance by backing out the reservation wage that is necessary to match the observed shopping trip and spending tax elasticities. This reservation wage ranges between $\$ 7$ and $\$ 10$, which seems reasonable given the average income of the households in our data, the fact that this wage is free from taxes and social security contributions, and that most people do not have the flexibility to work additional hours at their main job, but would have to take a secondary job (say driving for a rideshare company).

The model yields several additional insights. For instance, it shows that tax and price elasticities of spending can be very different, even with fully rational consumers and full tax salience. ${ }^{15}$ The reason is that most changes in (tax-exclusive) posted prices at the store level are unanticipated, while we find that sales tax changes are anticipated well in advance. If goods are storable, then unanticipated price changes prompt starkly different spending responses than anticipated changes. Moreover, sales tax changes are also much more persistent than posted price changes (both temporary sales promotions and "regular" or "reference" price changes). The perceived persistence of a price change also affects the spending response. Intuitively, consumers optimally stock up more in response to an unanticipated temporary price reduction (e.g., store sales) than to an unanticipated permanent price change, since the latter cannot be absorbed with inventory management. Hence, accounting for consumer expectations of tax and price changes is crucial when interpreting demand elasticities. ${ }^{16}$

Another insight from the model is that sales tax changes affect store traffic, because they apply to many goods at once. This extensive-margin effect is typically ignored in standard demand estimation but is important in the context of sales tax changes. Sales tax changes therefore provide a very different source of variation compared to the variation typically used in IO to estimate price elasticities of demand (e.g., product-specific cost or markup shocks). Moreover, we cannot use tax-exempt goods as a control group in a within-store or within-household differencein-differences setting, since tax-exempt goods are also affected by the anticipated tax change due to the shopping complementarity (a violation of the "stable unit treatment value assumption" in the terminology of program evaluations). In our case, such an approach would bias the estimates all the way to zero.

Finally, since shopping complementarity provides a novel channel, we present three additional pieces of evidence in support of this mechanism relative to the alternative that households are simply unaware of which goods are tax-exempt. First, we find that only consumers with high

Kilian and Stock (2017)). Much like in Hendel and Nevo (2006a, 2013), households in our model accumulate inventories because they expect prices to be higher in the future (speculative motive). However, our model further endogenizes trip timing and generates the shopping complementarity by including a shopping trip fixed cost (transaction motive). Consequently, while both models predict that households will store additional taxable goods in advance of a tax increase, only our model captures the spending response for tax-exempt goods and the extensive-margin shopping trip response we observe in the data.

${ }^{15}$ Coglianese, Davis, Kilian and Stock (2017) make a similar point in the context of excise taxes on gasoline.

${ }^{16}$ While this point might seem self-evident, an important consequence is that we cannot easily compare our results to demand elasticities typically estimated in the IO literature. The tax-induced price changes studied in this paper are well anticipated and affect a broad range of goods simultaneously, while demand elasticity estimates for individual goods typically use unanticipated, idiosyncratic price changes. 
shopping fixed costs stock up on both taxable and exempt goods. Consumers with low fixed costs on the other hand only stock up on taxable, but not on exempt goods. Second, shopping complementarities only apply to goods that are purchased on the same shopping trip. In line with this prediction, we find that online and mail order purchases only increase for taxable goods, because there are no or only few fixed costs to be shared for such purchases (e.g., common search costs). ${ }^{17}$ Third, the extent to which exempt spending responds also depends on the degree to which households can bundle their exempt and non-exempt spending. Households that shop at stores that sell solely exempt or solely taxable goods tend to have lower exempt spending responses. Households that typically shop at stores selling a mix of taxable and exempt goods tend to have higher exempt spending responses.

\section{Data}

Our empirical analysis uses three types of data: detailed high-frequency household retail spending scanner data at the product-by-store level, monthly combined sales tax rates at the 5digit ZIP code level, and data that complement our spending-based analysis by providing direct evidence of the fiscal implementation lag and fiscal foresight.

\subsection{Sales Tax Data}

For data on local sales tax rates, we turn to Thomson Reuters OneSource sales tax service. This source allows us to construct a database of ZIP code level sales tax rates at a monthly frequency from 2008 to 2014 that covers the entirety of the United States. The data contain comprehensive information on all sales taxes imposed in a given ZIP code stemming from the state, county, city, and from special tax rate districts that the ZIP code is located in, such as school or water districts, police jurisdiction, etc. Moreover, there is information on the combined sales tax in a ZIP code, which may differ from the sum of all of the aforementioned sales tax rates due to statutory maximum sales taxes imposed at a state level (e.g., state sales tax is $4 \%$ and the state imposes a maximum total local sales tax rate of 5\%) or the fact that a lower-level tax jurisdiction such as a city overrides the sales tax rate of a higher-level jurisdiction, such as state sales tax rate. Our final sample includes over 40,000 ZIP codes from 48 states and Washington DC, excluding Alaska and Hawaii which are not covered by Nielsen's scanner data.

Figure 1 shows the variability in both levels and changes of state and local tax changes, of which we have approximately 50 and 2,000, respectively. ${ }^{18}$

While sales taxes are not uniformly distributed over months in a year, we do not find that they

\footnotetext{
${ }^{17}$ Tax payers are in principle required to pay a 'use tax' to their home state when completing their annual taxes. However, compliance with the use tax is extremely low. For instance, only $0.3 \%$ of California tax returns reported any use tax related purchases in 2009.

${ }^{18}$ Several other papers (e.g., Cashin and Unayama (2016), D'Acunto et al. (2017)) study responses to large singular changes in VATs. The large number of sales tax changes across different states, cities, and localities allows us a great deal of power in assessing household responses. Having many potential changes allows us to control for business cycle or other time-related effects, to add state-period fixed effects, and to study differences in responses across tax changes of varying size.
} 
are excessively clustered in any particular month. January sales tax changes make up less than $20 \%$ of total sales tax changes. The first month of each quarter is overrepresented, with January, April, July, and October all exhibiting higher than average numbers of sales tax changes.

State sales taxes generally make up the majority of total sales taxes in a given ZIP code. We therefore augment our sample with hand-collected state level changes in sales tax rates from 2004-2008 to match the sample period of the retail scanner data described below. The average state-level sales tax change (in absolute value) is 0.61 percentage points and the $25^{\text {th }}$ and $75^{\text {th }}$ percentiles of state level changes are 0.25 percentage points and 1 percentage point. Local sales tax rate changes are similar both on average (mean 0.54 percentage points, median 0.5 percentage points) and in their dispersion (standard deviation of 0.37 percentage points vs. 0.38 percentage points for state level tax changes). Local changes are driven overwhelmingly by changes in city and county level taxes, while other sales taxes covering metro areas, water districts, school districts, or other geographic groupings play a much smaller role.

\subsection{Retail Spending Data}

Household-level retail spending data is obtained from the Nielsen Consumer Panel (NCP, formerly the Homescan Consumer Panel) and store-level retail sales are obtained from the Nielsen Retail Scanner Panel (NRP). The NCP consists of a long-run panel of American households in 52 metropolitan areas from 2004 to 2014. The NPC aimed at measuring household demographic characteristics, household income, and spending on retail goods. Using bar-code scanners and diary entries, participants are asked to report all spending on household goods following each shopping trip. Monetary prizes and other drawings are utilized to incentivize higher levels of engagement.

The NCP is constructed to be a representative sample of the US population. Demographic survey information about participants is obtained when they join the panel as well as each year thereafter. Nielsen attempts to maintain a high quality of data with regular reminders to participant households that prompt them to report fully, and will remove non-compliant households from their panel. ${ }^{19}$ Broda and Weinstein (2010) provide a more detailed description of the NCP. Einav, Leibtag and Nevo (2010) perform a thorough analysis of the NCP, finding generally accurate coverage of household purchases though having some detectable errors in the imputed prices Nielsen uses for a subset of goods. Overall, they deem the NCP to be of comparable quality to many other commonly-used self-reported consumer datasets.

Overall, there are more than 150,000 households in our sample. For the purposes of this paper, we choose to exclude households that change ZIP codes at any point in their time. This exclusion is done because we generally cannot tell the exact month of a move within a year, so any change in sales taxes that accompany such a move may generate a spurious relationship with observed retail spending. Following these exclusions, over 135,000 households remain, yielding over 6 million household-month observations.

\footnotetext{
${ }^{19}$ Approximately $80 \%$ of households are retained from year to year.
} 
Given the nature of the data collection, the NCP primarily covers trips to grocery, pharmacy, and mass merchandise stores. The types of goods purchased span groceries and drug products, small electronics and appliances, small home furnishings and garden equipment, kitchenware, and some soft goods.

To categorize individual products (Nielsen's 'Product Groups') into taxable or tax-exempt goods, we first categorize products into one of the following broad categories: groceries, clothing, prepared food, medication, beer, liquor, wine, cigarettes, and non-exempt goods. We choose these categories to cover the range of categories that are treated differently on a state-by-state basis when it comes to determining whether a product is exempt from the sales tax. We then assign the 119 Product Groups to these 9 broader exemption categories. For instance, "Crackers", "Dough Products", "Fresh Meat", and "Fresh Produce" would be Product Groups categorized as 'grocery' purchases. Groceries, in turn, are often exempt from any state or local sales tax. "Prepared Food Ready to Serve" is assigned to the "prepared food' category, while "Soft Goods" are treated as 'clothing'. The tax treatment of clothing or prepared food differs by state. Finally, a wide range of goods such as "Automotive" products, "Hardware and Tools", and "Toys and Sporting Goods" are categorized as 'taxable' since goods of that type are taxable in any state in the United States.

The ability to measure spending at a good-specific level, rather than at a merchant- or geographically-aggregated level (as in Cashin and Unayama (2016) or Agarwal et al. (2017)) is crucial to our ability to fully understand households' response to changes in sales taxes. Without this good-specific view, we would be unable to measure how spending shifts between exempt and taxable goods, and further substitution across merchants (e.g., to online or cross-border sales) would likewise be hidden. That is, good-specific data is required to conclude whether households are truly aware of sales taxes and respond in rational ways across the many potential dimensions of adjustment.

Overall, the NCP tracks a sizable amount of a household's spending on material goods. On average, we observe over $\$ 350$ of spending per month for each household. About half of this spending is on goods exempt from sales taxes while half is subject to sales taxes. Across states with sales taxes, only approximately $25-35 \%$ of total consumer spending is subject to sales taxes. This is largely due to the fact that almost all services are untaxed in most states, and households now spend over $50 \%$ of their total expenditures on services.

One concern with the NCP is sample selection since consumers who opt-in to the panel might not be representative based on unobservable characteristics, in particular how much attention they pay to sales taxes. To assess this issue, we also use store-level sales data from the Nielsen Retail Scanner Panel (NRP), which contains price and quantity information of each UPC carried by a covered retailer and spans the years 2006-2014. Nielsen provides the location of the stores at the three-digit ZIP code level (e.g., 602 instead of 60208), and we use a population-weighted average sales tax rate using the cross-walk provided by Thomson Reuters. 


\subsection{Other Data Sources}

To obtain direct measures of the fiscal implementation lag and of fiscal foresight by individuals, we use newspaper article counts and Google searches.

Newspaper Article Counts We employ data from the Access World News Newsbank database to measure news coverage of sales taxes at both a state and local level. ${ }^{20}$ We query a set of over 3,000 national, state, and local US newspapers at a monthly frequency from 2008 to 2016. Our query obtains the number of articles for each city-month or state-month that mention the term 'sales tax' or 'sales taxes'. We exclude classified ads and restrict our search to newspapers rather than newswires or magazines. Raw counts of articles may give a misleading measure of news coverage of sales taxes given changes in the number and size of newspapers at any given time. To better gauge relative news coverage, we normalize each monthly value by the total number of newspaper articles written in that month and location.

We conduct searches at two levels of geographic aggregation. The first is at a state level (including Washington DC as its own state). The second is at a city level, where we attribute newspapers to cities based on Access World News' categorization. Given that both our sales tax and retail spending data are at a ZIP code level, we match states and cities to ZIP codes using the city-state-ZIP matches in the Thomson Reuters sales tax data. This method yields a good match, with only 77 out of 1,468 cities with newspapers being unable to be matched to ZIP codes in our sample.

Google Searches We use Google search data obtained from Google Trends from 2004 to 2016 to study the search behavior of consumers around sales tax rate changes. Google Trends is a Google application that gives a time series of the relative amount of local search activity for specific search terms on Google.com. ${ }^{21}$ The values of Google Trends represent the number of searches on Google.com for the specified search term relative to the total number of searches on Google.com derived from a sample of all Google search data. Google Trends is normalized such that the highest value for the entire time period and term is set equal to 100. Its range of values is always between 0 and 100, where higher values correspond to higher ratios of total searches on Google.com for a given search term.

A potential concern, discussed in detail by Stephens-Davidowitz (2013), is that Google Trends imposes thresholds for reporting search data below which it imputes a zero value. For instance, too few searches were done for the search term 'econometrics' in July 2006 in Texas. Therefore, Google Trends displays a 0 rather than a low number, producing large swings in the time series data. For the term 'sales tax', there are a large number of zeroes between 2008 and 2010 in smaller states. We treat these values as missing data rather than true zeroes, due to the censoring that Google employs. In the years after 2010, there are only a few zeroes per year. Our results are

\footnotetext{
${ }^{20} \mathrm{http}$ ://www.newsbank.com/libraries/schools/solutions/us-international/access-world-news.

${ }^{21}$ http://www.google.com/trends.
} 
robust to excluding all data from the years prior to 2011 or excluding smaller states altogether from the estimation.

\section{Research Design}

Our primary empirical methodology is to utilize a difference-in-differences specification with relatively high-frequency spending data at the household/store-month level. The economic interpretation of our empirical results depends crucially on whether the tax changes were anticipated. If tax changes are anticipated, then spending changes and shopping behavior around the tax changes documented in later sections reflect substitution effects, while income and wealth effects take place at the time households learn about an upcoming tax change.

This section therefore provides direct evidence of the long lag between the date when a tax change is legislated and the date when the tax change is finally implemented (i.e., the implementation lag) and of fiscal foresight on the part of individuals. Unfortunately, for the multitude of changes in local tax rates, we do not know the dates at which the tax changes were legislated on. Analysis of a selected set of tax rates suggests that, on average, a tax rate is decided on 6 to 9 months in advance of the change being implemented. More broadly, using newspaper article ratios, we document that the news media covers upcoming sales tax rate changes well in advance. Hence, households have easy access to relevant sale tax information well in advance of the tax changes. More importantly, using Google Search data we show that some households actively acquire information about sales tax rates in advance of the tax rate changes. Both results are consistent with our findings in Section 4 below that households adjust their spending patterns around sales tax changes.

Difference-in-Differences Approach For most of our examination of the impact of changes in sales tax rates, we look at monthly changes in spending and shopping behavior at a household or store level. By construction, the control groups are those households/stores who did not experience a change in the sales tax rate that they face in that month. All regressions include both period and household/store-level fixed effects, thus controlling for seasonal effects, macroeconomic effects, and allowing for household/store-level trends over time.

We estimate the response of various outcomes to changes in total and state sales taxes, respectively, using a difference-in-differences approach by running regressions of the following form:

$$
\Delta y_{h t}=\beta \Delta \ln \left(1+\tau_{j t}\right)+\gamma_{h}+\theta_{t}+\lambda^{\prime} z_{h t}+\varepsilon_{h t} .
$$

$\Delta y_{h t}$ is the change in the outcome of interest in month $t$ by household or store $h$. We consider several outcome variables, including the log of pre-tax expenditures on taxable goods (i.e., expenditures evaluated at posted pre-tax prices), log expenditures on tax-exempt goods, log online and mail-order purchases, the fraction of spending done in a neighboring tax jurisdiction, and measures of shopping frequency. $\Delta \ln \left(1+\tau_{j t}\right)$ is the log-change of the gross of sales tax rate (since 
sales taxes are ad valorem) in that month in the corresponding tax jurisdiction $j$, a zip code or a state (our results are little changed when utilizing the percentage change in sales taxes rather than the logged gross change in prices). $\gamma_{h}$ are household/store fixed effects and $\theta_{t}$ are period fixed effects (year and month indicators). $z_{h t}$ are additional time-varying co-variates at the level of the household, store or tax jurisdiction.

Fiscal Implementation Lag Figure 2 shows two metrics of the fiscal implementation lag and of fiscal foresight in the months surrounding state sales tax rate changes. The top panel displays the evolution of the ratio of news articles that mention sales taxes in the 10 months before and after a change in sales tax rates. It displays the regression coefficients of estimating a dynamic version of equation (1) with the log-level of the newspaper article ratio on the left-hand side and leads and lags of monthly state sales tax rate changes as the main dependent variable while controlling for state and time fixed effects. The dashed lines represent $95 \%$ confidence intervals using standard errors clustered at the state level. We find a gradual increase in articles, with the article ratio being significantly higher than the baseline level starting approximately 6 months prior to the change. In the month before the change occurs, the peak ratio is about $75 \%$ higher than the baseline. Since this figure is scaled by the size of the change, larger sales tax changes tend to get more news coverage relative to smaller changes. Following the change, news about sales taxes quickly recedes to the baseline level, with the ratio being statistically indistinguishable from zero just one month following the change.

Fiscal Foresight While the top panel shows that households have in principle read access to the latest information about upcoming sales tax changes, it remains to show that households actively acquire this information. The bottom panel of Figure 2 shows that households indeed increase the search for information about sales taxes in anticipation of a sales tax change. The figure plots the coefficients of the same specification as before, replacing the newspaper article ratio with the Google Search index. As with the newspaper-based measure, search peaks in the month before a change takes place, rising to over $130 \%$ of the baseline level of search. Google searches about sales taxes do not respond as far in advance of the change occurring, but have significantly elevated levels for a longer period than does the news-based measure. This may reflect a subset of households only realizing sales taxes may have changed over a longer period.

\section{Response of Spending and Shopping Behavior}

\subsection{Taxable Spending}

Table 1 shows how retail sales of goods subject to sales taxes change following a change in the sales tax rate. We restrict the main analysis to tax increases both because the vast majority of tax changes in our sample period are tax increases and because the model below featuring storable and durable goods implies an asymmetric response to sales tax changes. Stocking up 
before a sales tax increase is easier and more likely synchronized across households in the month before the tax increase compared to letting inventories of storable and durable goods deplete in anticipation of a sales tax decrease. ${ }^{22}$

Panel A documents the main results of the analysis. Column 1 shows that following an increase in the combined total sales tax rate of one percentage point (e.g., from $3 \%$ to $4 \%$ ), taxable household retail spending decreases by $2 \%$. This change in spending is measured in the month of the tax change relative to the month prior. ${ }^{23}$ Column 2 restricts the analysis to state sales tax increases, which allows us to extend the analysis back to 2004, the start of the Nielsen Consumer Panel. The sales tax elasticity of taxable expenditures is almost identical to the one estimated using total sales tax changes in Column 1, although it is estimated with less precision due to the fewer tax changes (despite the longer sample period).

Panel B tests the robustness of this result. Column 4 shows that controlling non-parametrically for time-varying household characteristics like income and family composition has little impact on the size of the sales tax elasticity of taxable spending. Column 5 adds in local and state unemployment rates to control for local business cycle conditions. We see little change in the coefficient of interest following the addition of these controls. Similarly, dropping the months from January 2008 to June 2009 that were part of the Great Recession according to the NBER recession dating committee also sees little change in the estimates, as seen in Column 6. In Column 7 we utilize only within-state variation in sales taxes, including highly granular state-year and state-month fixed effects, and find that the magnitudes of our estimates remain virtually unchanged.

Consumers can respond to an anticipated sales tax increase using four main margins of adjustment: moving purchases of storable and durable goods forward to the months before a sales tax increase (and potentially also consumption), shifting spending online and not paying use taxes, shopping in a neighboring tax jurisdiction with a lower sales tax rate, and substitution consumption from taxable to exempt goods. Columns 8 and 9 sequentially shut down the second and third margin (which are the focus of Section 7), thereby restricting the response to intertemporal substitution, while Section 4.2 below analyzes the extent to which households substitute consumption from taxable to exempt goods in the long run. Column 8 restricts the sample to households that did not do any online and mail order purchases in that year, and Column 9 further restricts the sample to households that also do not purchase products in an alternative three-digit ZIP code outside of their own home ZIP code. As one might expect, the point estimates are larger in absolute value for such households that can only respond by engaging in intertemporal substitution, but we cannot reject that the response is the same as in the full sample. The small difference in the response reflects the fact that cross-border and online shopping only makes up a small fraction of purchases for most consumers in the NCP.

\footnotetext{
${ }^{22}$ However, Column 3 shows that we obtain comparable results when analyzing only tax decreases.

${ }^{23}$ The vast majority of sales tax changes go into effect on the first of the month, so the entire month is under the new sales tax rate. Our estimates are robust to excluding or weighting sales tax changes that occur on a different day of the month (the $15^{\text {th }}$ is the second most common day).
} 
As mentioned above, one concern with the NCP is that consumers that select into the panel might not be representative based on unobservable characteristics, in particular how much attention they pay to sales taxes. In Panel $\mathrm{C}$ we address this issue directly by using store-level data from the Nielsen Retail Scanner Panel (NRP) instead of the household-level NCP data. We find slightly larger responses than in the NCP data, although we again cannot reject the hypothesis that the two estimates are the same because of the larger standard errors of the store-level estimates. However, we would expect larger responses in the store-level data because, while households can take steps to maintain their levels of spending by shifting to untaxed or less-taxed jurisdictions, stores have fewer margins to adjust their exposure to a sales tax increase in the short run.

\subsection{Intertemporal Substitution}

Any consumer who is aware of an upcoming sales tax increase can at least temporarily avoid paying a higher tax by moving spending forward, even if he does not have the opportunity to shop online or to shop in a neighboring tax jurisdiction with a lower sales tax rate. Hence, intertemporal substitution is the most general adjustment mechanism and this section explores the extent to which consumers take advantage of it.

Intertemporal substitution is also the only margin of adjustment that requires consumers to be forward-looking. Tax incentives for the other two margins of adjustment, cross-border shopping and substitution to online purchases, only change when tax rates change. Estimates of these margins therefore do not test forward-looking behavior.

Shopping Behavior and Intertemporal Substitution Consumers can move both consumption or spending forward to periods with low tax rates. If goods are storable or durable, then these two forms of intertemporal substitution are not the same since consumers can purchases storable goods in advance of the sales tax increase even if they do not change their consumption behavior. ${ }^{24}$ If intertemporal substitution of consumption is low, then increases in inventory purchases should decrease the shopping frequency as a larger inventory can support the same consumption rate over a longer period. Hence, comparing the tax elasticity of shopping trips with the tax elasticity of spending provides useful information about the elasticity of intertemporal consumption substitution, a point which the model in Section 5 establishes more formally.

Panel D of Table 1 shows that the number of distinct store visits responds negatively to increases in sales tax rates. The number of trips falls by a similar amount as overall spending, suggesting that the trips adjustment margin is a dominant one. This finding is robust to controlling for household characteristics and for business cycle conditions. Moreover, this extensive margin elasticity is estimated substantially more precisely than the spending elasticity, with standard errors that are $30 \%$ smaller.

\footnotetext{
${ }^{24}$ Again, this analysis focuses on substitution effects that happened after any income and wealth effects have taken place, which typically happens when consumers learn about the upcoming tax increase.
} 
Fiscal Foresight and Intertemporal Substitution Since sales taxes are almost always announced significantly in advance, we might expect that changes in household behavior precede the effective date of the sales tax change if households are forward-looking and are aware of upcoming sales tax changes. To test this prediction, we estimate a dynamic version of equation (1), regressing levels of taxable and tax-exempt spending on leads and lags of the sales tax rate changes. For example, a positive coefficient in period $t=-2$ indicates an increase in sales tax two periods in the future tends to drive higher than average levels of spending in a given period.

Figure 3 plots the patterns of spending in the months surrounding a change in state sales taxes that is scaled to reflect a 1 percentage point tax increase. We find elevated levels of spending in the period preceding a sales tax increase that quickly disappear once the change takes effect. For a sales tax increase of 1 percentage point, we see a dramatic fall in spending in the month of the change (period 0) relative to the previous months (period -1), equivalent to a decline in spending of about $2.5 \%$, similar to the more static responses reported in Table 1.

As seen in Figure 3, and across a range of specifications, we find that the average deviation from the household's shopping trend converges to zero relative to the pre-tax-change period. That is, the short-term response of household spending is significantly different than, and greater than, any long-term response. Interestingly, exempt goods see a similar build-up prior to the tax increase and undergo a similar fall in the months afterwards. We study the response of tax-exempt goods to a change in sales tax rates in more detail in Section 4.4 below.

Storability and Intertemporal Substitution Given the revealed desire to shift spending forwards in time, we would expect to see this substitution manifest itself to a larger degree for goods that are more durable or more storable. That is, it would not be feasible to purchase a several-month supply of baked goods given that it would go bad before it could all be used.

To examine whether this pattern holds true empirically, we must first categorize all products in the Nielsen Consumer Panel data by their durability and storability. We do so in two ways. First, we use average purchasing patterns in the data to inform us about the storability of each product. To do so, we categorize each product group with a continuous measure of how frequently products in a given group were purchased. For instance, carbonated beverages, purchased every other week by an average household, would have a value of approximately $\frac{1}{2}$ ( 2 average purchases per month), while women's fragrances may have a value greater than 12 (purchased less than once a year). This 'shopping cycle', which is the purchase frequency of a typical product in product group $g$, is calculated first at a household level and then averaged across all households in the sample,

$$
\text { Storability }_{g}=\ln \left(\frac{1}{N_{H}} \sum_{h=1}^{H} \frac{1}{T_{h}} \sum_{s=1}^{S_{h}} \mathbb{1}\left\{\operatorname{Trip}_{s g}\right\}\right)^{-1}
$$

$\mathbb{1}\left\{\operatorname{Trip}_{s g}\right\}$ denotes whether shopping trip $s \in S_{h}$ is one in which household $h$ made a purchase from product group $g$. $T_{h}$ measures the total number of months household $h$ is in the sample 
and $N_{H}$ represents the total number of households in the overall sample.

This first measure of storability and durability has the advantage that it is good-specific and continuous. However, it does not capture certain cases well. ${ }^{25}$ We therefore supplement our analysis with a binary measure of durability following previous literature on storable and durable goods (e.g. Cashin (2017)) by manually categorizing the 119 product groups contained in the Nielsen data into durable or storable groups.

The last two columns of Table 2 show the product groups sorted from highest to lowest number of times a product is purchased in this group per month (or from lowest to highest shopping cycle). The measures of storability and durability correspond fairly well, with durable goods on average having significantly lower purchases per month (0.3) than goods that are not classified as durable (0.8). However, the correlation coefficient is only 0.5 reflecting the fact that many non-durable products are fairly storable. Column 8 shows that the average taxable product is purchased slightly less than once a month suggesting that monthly aggregation of purchases is a sensible choice when analyzing household-level data as in Table 1 rather than product-level data as in Table 2.

We conduct our analysis of heterogeneous behavior across categories of goods at a statemonth level by regressing log-changes in pre-tax expenditures on taxable goods in (1) on state sales tax changes interacted with the one of the two measures of product storability and durability, either the continuous average inverse purchase frequency or the discrete hand-classified durability indicator. Collapsing the data to the state-month level minimizes problems that arise from individual households having large numbers of zeroes for their monthly spending on particular fine categories, but also substantially reduces the number of observations and the power since we restrict the tax variation to state tax changes.

Table 2 reports results from this analysis. Column 1 shows the baseline spending response to a change in state sales taxes. On average, across categories, we see a decline in spending of approximately $2.5 \%$ in the month of a sales tax increase of 1 percentage point. This state-level estimate corresponds well with our individual household-level responses of approximately $2.2 \%$ (Column 2 of Table 1). Column 2 includes the lead of increases in state level sales taxes to analyze intertemporal substitution patterns. That is, for the month of each state sales tax change, we observe the response of spending for the month prior to the change as well as the month after. We see that consumers indeed bring spending forward to the month before the sales tax rate increases.

Since there is a lot of heterogeneity in storability and durability of taxable products, this average response is estimated imprecisely. In Panel B we therefore interact the change in sales tax rates with our measures of product durability and storability. Column 3 uses the simple binary indicator for durability while Column 4 uses our continuous measure of storability, the product group level data on inverted logged purchase frequency. We find that products purchased

\footnotetext{
${ }^{25}$ For instance, many consumers might buy turkey meat only once a year, which does not reflect its storability but its seasonal demand as a traditional Thanksgiving dinner.
} 
more frequently tend to be less affected by a change in sales taxes while infrequently purchased products see a larger than average response in the month of the tax change (Column 4). To relate our new measure to the previous literature, Column 3 uses the simple indicator for durability as an interaction variable. Here we find a negative point estimate but it is not statistically different than zero.

In Columns 3 and 4, we find that not only do more durable and more storable products have larger declines in the month of a sales tax increase, but they also see larger build-ups in the month prior to the increase. In fact, durable and storable products are the only product categories that see any increase in spending in the month before a sales tax increase.

To show the tremendous heterogeneity in responses by storability, in Column 5 we interact the sales tax changes (both current and lead) with the quartiles of the storability measure. We see an enormous range of demand elasticities. Purchases of products in the top quartile of storability increase by $15 \%$ the month before a 1 percentage point sales tax increase and then fall by $13 \%$ in the month of the tax change.

These results are consistent with recent studies of intertemporal household spending behavior. Cashin (2014) for instance also finds that this pattern was seen around changes in the sales tax rate in New Zealand. Using data regarding three substantial changes in the national sales tax (Goods and Services Tax) rate, he finds strong evidence for intertemporal substitution among both durables and non-durables. Consistent with our estimates he finds that the magnitude of the substitution from the month of the change to the month prior to the change is 3 to 5 times larger for durable or storable goods than for non-durable and non-storable goods.

Accounting for a product's storability is very important when price changes are anticipated. The reduced-form elasticity in Column 1 (and the elasticities in the other tables) represents a local average tax elasticity across many different products with different tax elasticities, potentially highly related to differences in storability and durability. When extrapolating our estimates, policymakers therefore need to take into account two factors that have opposite effects on the tax elasticity of aggregate consumer spending. On the one hand, as mentioned in Section 2.2, the proportion of tax-exempt services is higher in the broader economy than is seen in the Nielsen data, which only covers consumer goods. In the next subsection we shows that spending on taxexempt consumer goods also responds to sales tax changes due to shared shopping trip costs. To the extent that services not covered by Nielsen (e.g. healthcare spending, rent) have relatively low shopping complementarities with taxable goods, this would reduce the tax elasticity of aggregate consumer spending relative to our estimates.

On the other hand, Nielsen also does not cover some significant taxable expenditure categories such as large durables. For example, three primary categories of taxable goods that are unobserved in our data are automobiles, large consumer electronics and 'white goods' (e.g. washing machines and refrigerators). Given that these items are much more durable than the average taxable good observed in our sample, accounting for them would likely increase the tax elasticity of aggregate consumer spending. 


\subsection{Price and Quantity Response}

While the majority of the paper discusses household responses in terms of changes in dollars of retail spending, it is possible that this may portray an incomplete view of household behavior. If retailers adjust prices or households shift spending to different types of goods, we may have a different interpretation of how the pre-tax spending response relates to actual consumption.

Table 3 examines two other important margins. Columns 1 to 4 mirror the analysis done in Table 1 but using log-changes of quantities (items) purchased as the dependent variable rather than log-changes in spending. We find qualitatively similar effects, with declines in quantities mirroring the declines in spending following an increase in sales tax rates. This indicates that households are likely not simply substituting lower quality and lower priced goods to reduce pre-tax spending.

Columns 5 to 8 test another potential confounding margin of adjustment. If retailers fully offset sales taxes, we might observe a decline in pre-tax spending with no actual decline in total (tax-inclusive) spending. Using data on both retail and wholesale prices we find that there is limited amounts of offsetting behavior on the part of firms. Retail prices decline by $0.15 \%-0.20 \%$ in the month following a 1 percentage point increase in sales tax rates, while wholesale prices remain unaffected.

Wholesalers tend to have much more stable prices, with fewer short-term sales than do retailers. Moreover, they less geographically concentrated and do not price to highly local conditions to the same extent that retailers do. Thus, a near-zero response from such wholesalers may be less surprising than among retailers themselves. We leave a more complete analysis of the firm response to sales tax changes, taking into account the response of demand documented in this paper, to future research.

\subsection{Tax-Exempt Spending}

In theory, we might expect that the effect of a sales tax increase on tax-exempt spending would be zero, or would mainly capture income or wealth effects of the tax reform. Hence, if we do not think that there are strong patterns of substitution between taxable and tax-exempt goods, tax-exempt spending could be used as a natural 'control group' to estimate the effect of a tax change using a within-household difference-in-differences specification. However, there are a few reasons why we might still see an effect even for goods that are not directly affected by sales tax rate changes. Households may be unaware of the fact that some goods are exempt from sales taxes or may simply mis-attribute an exempt product to a non-exempt category. After all, the laws defining which goods are exempt and non-exempt are quite detailed and technical, so it would not be surprising to have a significantly level of this sort of error on the part of households.

In addition, sales tax changes apply to many goods at the same time and hence are different from idiosyncratic (pre-tax) price changes typically used to estimate demand. In addition to income effects mentioned above, sales tax changes can thus also affect store traffic in the same 
way deals or large store sales are used by retailers for the purpose for cross-selling other goods with higher margins that are not on sale. In this section we therefore analyze the response of tax-exempt spending in order to assess the total effect of a sales tax rate increase on retail spending.

Table 4 reports the response of tax-exempt spending in the month of a sales tax rate increase relative to the previous month, mirroring the exact specifications seen in Table 1 . We find a highly significant response of exempt spending to changes in both state and local sales taxes. This effect remains when limiting the analysis to state sales tax changes and when controlling for household characteristics and local business cycle conditions. Our estimates for tax-exempt goods are lower than for taxable goods, but both are significantly different than zero and are statistically indistinguishable from one another. Figure 3 shows that tax-exempt spending mimics the behavior of taxable spending not only in the month of the sales tax increase but also in the months surrounding that tax change.

Overall, the impacts from changes in sales tax changes on tax-exempt goods are similar to those found for taxable goods. The effect is again larger for store-level sales as shown in Panel $\mathrm{C}$ (since they are fully exposed to the policy while some consumers can partially avoid the taxes as shown in Section 7), paralleling the larger response of taxable sales in Panel C of Table 1, although even larger in the case of tax-exempt products.

\section{A Model of the Shopping Response to Sales Taxes}

Because we find evidence that complementarities in shopping for both taxable and exempt goods seem to drive household spending, we develop a model of household shopping to determine whether such behavior can be rationalized both qualitatively and quantitatively. ${ }^{26}$ In the model, rational forward-looking consumers know about an upcoming sales tax increase at date $t_{\tau}$ and choose consumption continuously. This setting corresponds to our main empirical research design which focuses on the high-frequency spending response around a sales tax increase, but after the upcoming sales tax change has been announced. Hence, these are compensated changes after the direct wealth effect of the higher future tax rate has already been incorporated into the steadystate consumption levels. Moreover, because these tax changes occur relatively infrequently within a tax jurisdiction, we use a perfect-foresight model. Consumers face transaction fixed costs of shopping (e.g., time spent shopping, search costs, etc.) and therefore choose discretetime transaction dates $t_{n}$ in order to maximize lifetime utility

$$
\int_{t=0}^{\infty} e^{-\rho t} u(C(t)) d t
$$

with instantaneous utility $u(C(t))=\frac{C^{1-1 / \sigma}}{1-1 / \sigma} \cdot C(t)=\left(\sum_{i} b_{i}^{1 / \eta} c_{i}(t)^{1-1 / \eta}\right)^{\frac{\eta}{\eta-1}}$ is the composite good consisting of taxable good $c_{\tau}(t)$ and a tax-exempt good $c_{e}(t)$, where $\eta$ is the intra-temporal elas-

\footnotetext{
${ }^{26}$ To save space, we provide the more detailed derivation of the model in Appendix B.
} 
ticity of substitution between consumption of taxable and exempt goods. The household receives a constant flow of earned income $y$ and can invest either in a risk-free asset $a$ with continuously compounding return $r$ or in inventories $s_{i}$ of storable consumer goods which depreciate at rate $\delta .^{27}$ For notational simplicity and without much loss of generality, assume that the starting date of the analysis, date $t=0$, is a transaction date. The intertemporal budget constraint is

$$
a_{0}+\int_{t=0}^{\infty} e^{-r t} y d t=\sum_{n=0}^{\infty} e^{-r t_{n}} K_{t_{n}}
$$

with initial financial assets $a_{0}$ and transversality condition $\lim _{n \rightarrow \infty} e^{-r t_{n}} a_{t_{n}}=0 .{ }^{28} K_{t_{n}}$ are the total shopping trip costs that occur at transaction date $t_{n}$ and include the fixed costs per trip $\kappa$ and total consumption expenditures $P_{t_{n}} S_{t_{n}}$,

$$
K_{t_{n}}\left(C_{t_{n}}, \Delta t_{n}\right)=\kappa+P_{t_{n}} S_{t_{n}}\left(C_{t_{n}}, \Delta t_{n}\right)
$$

$C_{t_{n}}$ denotes instantaneous consumption of the composite good at the beginning of the endogenously chosen period of length $\Delta t_{n}=t_{n+1}^{-}-t_{n}$, where $t_{n+1}^{-}$is the limit from below of the next transaction date $t_{n+1}$.

$S_{t_{n}}$ is the necessary beginning-of-period inventory of the composite good to support consumption until the next transaction date. Inventory $s_{i}(t)$ of good $i$ solves the differential equation $\dot{s}_{i}(t)=-\delta s_{i}(t)-c_{i}(t)$ at any point during the shopping interval. Because there is no uncertainty, there is no precautionary inventory demand and households optimally exhaust inventories fully right before the next shopping trip, $s_{i}\left(t_{n+1}^{-}\right)=0$. This terminal condition determines the necessary initial inventory at the beginning of the shopping cycle. The expenditure-minimizing cost of a unit of the composite consumption good purchased at date $t_{n}$ is $P_{t_{n}}=\left(\sum_{i} b_{i} p_{i, t_{n}}^{1-\eta}\right)^{1 /(1-\eta)}$ and Hicksian demand is $c_{i, t_{n}}=b_{i}\left(\frac{p_{i, t_{n}}}{P_{t_{n}}}\right)^{-\eta} C_{t_{n}}$. Total expenditures at the beginning of the shopping interval can be expressed in terms of inventory of the composite good, $P_{t_{n}} S_{t_{n}}=\sum_{i} p_{i, t_{n}} s_{i, t_{n}}$, with $s_{i, t_{n}}=b_{i}\left(\frac{p_{i, t_{n}}}{P_{t_{n}}}\right)^{-\eta} S_{t_{n}}$. Defining

$$
f\left(\Delta t_{n} ; \alpha\right)=\int_{t=0}^{\Delta t_{n}} e^{\alpha t} d t=\frac{e^{\alpha \Delta t_{n}}-1}{\alpha}
$$

\footnotetext{
${ }^{27}$ Given that we model goods as decaying exponentially, the assumption that depreciation across goods is equal is unlikely to substantially alter our results regarding shopping complementarities. Exponential decay implies that the amount of stocking up that occurs in advance of a tax increase is determined by a weighted average durability and not by the most perishable good. Adding good-specific depreciation to the model would allow the household to substitute along the margin of product choice - consuming fewer perishable goods around the time of the tax increase. In practice, consuming highly perishable goods does necessitate frequent trips to the store. But, in reality, a household may either forgo highly perishable goods temporarily or purchase such goods separately at a store with lower trip costs - both of which are still consistent with a relatively strong shopping complementarity. Indeed, though there is only one store location in the model, the practical possibility of a corner store with low trip cost but higher prices or limited products seems consistent with the insignificant spending response for highly perishable items in the data.

${ }^{28}$ We write continuous time variables as $x(t)$ and discrete time variables as $x_{t_{n}}$, where $x_{t_{n}}=x\left(t_{n}\right)$ is the value of $x$ at the beginning of the endogenously chosen transaction interval.
} 
the consumer purchases $S_{t_{n}}=C_{t_{n}} \cdot f\left(\Delta t_{n} ; \phi\right)$ at date $t_{n}$ given price index $P_{t_{n}}$, where $\phi=\delta-\sigma(\delta+\rho)$ is the effective discount rate of utility over the transaction interval $\Delta t_{n}$, which accounts for the pure time preference, the user cost of inventory, and the consumer's willingness to shift consumption intertemporally within a period between two shopping transactions.

We formulate this problem as a dynamic program by discretizing the consumption plan to match the shopping intervals, building on an early model by Howitt (1977). For this purpose, we define the indirect utility function of consumption between shopping transactions as

$$
\begin{aligned}
U\left(C_{t_{n}}, \Delta t_{n}\right) & =\max _{\{C(t)\}}\left\{\int_{x=0}^{\Delta t_{n}} e^{-\rho x} u\left(C\left(t_{n}+x\right)\right) d x: \int_{x=0}^{\Delta t_{n}} e^{\delta x} C\left(t_{n}+x\right) d x=S_{t_{n}}\right\} \\
& =u\left(C_{t_{n}}\right) \cdot f\left(\Delta t_{n} ; \phi\right) .
\end{aligned}
$$

Defining total wealth $w_{t_{n}}=a_{t_{n}}+y / r$, the problem can be written as a dynamic program,

$$
V\left(w_{t_{n}}\right)=\max _{C_{t_{n}}, \Delta t_{n}}\left\{U\left(C_{t_{n}}, \Delta t_{n}\right)+e^{-\rho \Delta t_{n}} V\left(w_{t_{n+1}}\right): w_{t_{n+1}}=e^{r \Delta t_{n}}\left(w_{t_{n}}-K_{t_{n}}\right)\right\}
$$

The envelope theorem requires that an additional dollar received at the beginning of each transaction period has the same present utility value,

$$
V_{t_{n}}^{\prime} e^{-r \Delta t_{n}}=e^{-\rho \Delta t_{n}} V_{t_{n+1}}^{\prime}
$$

Optimal consumption and beginning-of-period inventory of the composite good are characterized by the first-order condition

$$
\partial_{C} U_{t_{n}}^{\prime}=\partial_{C} K_{t_{n}}^{\prime} \cdot V_{t_{n}}^{\prime}
$$

$\partial_{C} K_{t_{n}}^{\prime}=P_{t_{n}} f\left(\Delta t_{n} ; \phi\right)$ is the effective price of consumption taking into account the inventory costs. Combining equations (5) and (6) we obtain the familiar Euler equation for the growth rates of unobserved beginning-of-period consumption,

$$
\frac{C_{t_{n+1}}}{C_{t_{n}}}=e^{\sigma(r-\rho) \Delta t_{n}}\left(\frac{P_{t_{n+1}}}{P_{t_{n}}}\right)^{-\sigma},
$$

and of observable beginning-of-period inventory of the composite good,

$$
\frac{S_{t_{n+1}}}{S_{t_{n}}}=\frac{C_{t_{n+1}}}{C_{t_{n}}} \cdot \frac{f\left(\Delta t_{n+1} ; \phi\right)}{f\left(\Delta t_{n} ; \phi\right)} .
$$

The less familiar necessary condition determining the optimal transaction interval is

$$
\partial_{\Delta t} U_{t_{n}}^{\prime}-\partial_{\Delta t} K_{t_{n}}^{\prime} \cdot V_{t_{n}}^{\prime}=e^{-\rho \Delta t_{n}}\left[\rho V_{t_{n+1}}-r w_{t_{n+1}} \cdot V_{t_{n+1}}^{\prime}\right]
$$

The left-hand side captures the net marginal utility at date $t_{n}$ of increasing the time until the next 
shopping transaction at date $t_{n+1}$, which equals the present value of the additional consumption utility net of the additional cost to support the extension of the transaction interval. The terms in square brackets on the right-hand side capture the net marginal cost from starting the next period later, which equals the cost from delaying the continuation value net of the additional interest earned.

Steady State From equation (5) we see that the stationary state, which starts at the first transaction date $t_{s s}$ after the tax increase, requires $r=\rho$ unless the value function is linear. The optimal inventory and transaction intervals in the stationary state are jointly determined by combining equations (4) to (6),

$$
(1-\sigma) \frac{\kappa}{P_{t_{s s}} S_{t_{s s}}}=e^{\phi \Delta t_{s s}} \frac{f\left(\Delta t_{s s} ; r\right)}{f\left(\Delta t_{s s} ; \phi\right)}-1,
$$

and by the budget constraint in the stationary state $w_{t_{s s}}=\left(1-e^{-r \Delta t_{s s}}\right)^{-1}\left(P_{t_{s s}} S_{t_{s s}}+\kappa\right)$. In the stationary state, the consumer trades off the additional user cost by marginally extending the shopping trip interval against the marginal benefit of pushing the fixed costs further into the future. To gain intuition, we can related this condition to the familiar square-root formula from static inventory models if we assume that the consumer is unwilling to substitute consumption intertemporally $(\sigma=0)$ and if we take a second-order approximation of $(9)$ around $\Delta t_{s s}=0$,

$$
\Delta t_{s s} \approx \sqrt{\frac{\kappa}{\frac{\delta+r}{2} P_{t_{s s}} C_{t_{s s}}}} .
$$

Higher transaction fixed cost as a fraction of total spending per trip lead to less frequent shopping, while higher user costs (depreciation and forgone interest) lead to more frequent shopping. However, in general with $\sigma>0$ this is not a good approximation.

\subsection{Shopping Response to an Anticipated Sales Tax Increase}

Figure 4 shows the evolution of composite consumption and inventories (left y-axis), the increase in the price index due to an anticipated sales tax increase (right y-axis) and endogenously chosen transaction intervals (x-axis). To make this example as stark as possible, we use a very large tax change of 10 percentage points and an unrealistically large elasticity of intertemporal substitution of 6 and a low fixed cost of $\$ 2$. Both choices are made only for this figure.

Because the sales tax increase is fully anticipated by forward-looking consumers, the problem of choosing consumption, inventories, and transaction dates is non-stationary and standard inventory models cannot easily be applied to this setting. However, as the figure shows, we can divide the solution into three stages: (i) the pre-period shopping intervals $\left(\Delta t_{s s-q}\right.$ for $\left.q \geq 2\right)$ that occur while the consumer faces the old sales tax rate in the current and the next shopping trip, (ii) the interim shopping interval $\Delta t_{s s-1}$, which is the last trip before the tax increase, and (iii) the final stationary state of shopping intervals $\Delta t_{s s}$ that occur under the new sale tax rate. 
Tax Elasticities Next we derive analytic expressions for the tax elasticities of the key variables in the model - consumption, inventory, and shopping intervals - and map them to the observed spending and trip elasticities estimated in Section 4. The consumption Euler equation governs the wealth-compensated consumption elasticity to an anticipated sales tax increase at the time of the tax change (i.e., after the consumer has been informed about the new tax rate and hence after the wealth effect on the steady-state consumption level has been incorporated),

$$
\begin{aligned}
\varepsilon_{c_{i}} \equiv \frac{d \ln \left(c_{i}\left(t_{s s}\right) / c_{i}\left(t_{s s-1}\right)\right)}{d \ln \left(1+\tau_{t_{s s}}\right)} & =-(\sigma-\eta) \frac{d \ln \left(P_{t_{s s}} / P_{t_{s-1}}\right)}{d \ln \left(1+\tau_{t_{s s}}\right)}-\eta \frac{d \ln \left(p_{i, t_{s s}} / p_{i, t_{s s-1}}\right)}{d \ln \left(1+\tau_{t_{s s}}\right)} \\
& =-(\sigma-\eta) B_{\tau}-\eta 1_{\{i=\tau\}} .
\end{aligned}
$$

The second line uses $d \ln \left(P_{t_{s s}} / P_{t_{s s-1}}\right) / d \ln \left(1+\tau_{t_{s s}}\right)=B_{\tau}$, where $B_{\tau}=p_{\tau, t_{s s}} s_{\tau, t_{s s}} /\left(P_{t_{s s}} S_{t_{s s}}\right)$ is the expenditure share of taxable goods in steady state. For taxable goods, the reduced-form consumption elasticity is unambiguously negative (or non-positive), while the sign of the elasticity of tax-exempt consumption depends on the relative size of the two structural elasticities, the intertemporal substitution elasticity $\sigma$ and the intratemporal substitution elasticity $\eta$.

The two reduced-form consumption elasticities $\varepsilon_{c_{\tau}}$ and $\varepsilon_{c_{e}}$ are not directly observable in the data since consumption differs from spending. Moreover, substitution of consumption is not the only or even the main adjustment margin available to consumers. Instead, consumers can also respond by bringing spending forward and thereby extending the time until the first transaction under the higher tax rate. Using (7) and (9), the increase in the length of the interim shopping interval $\Delta t_{s s-1}$ (and hence the start date $t_{s s}$ of the steady state under the higher tax rate) can be expressed in closed form as

$$
\Delta t_{s s-1}-\Delta t_{s s}=\frac{\ln \left(P_{t_{s s}} / P_{t_{s-1}}\right)}{\delta+r}
$$

The consumer trades off the marginal return from bringing spending forward before taxes increase (numerator) against the additional user cost incurred during the shopping interval (denominator). The shopping interval does not change unless the price level is expected to change. Therefore, the structural interpretation of the short-run elasticity of the shopping trip interval is

$$
\varepsilon_{\Delta t_{s s-1}} \equiv \frac{d \ln \left(\Delta t_{s s} / \Delta t_{s s-1}\right)}{d \ln \left(1+\tau_{t_{s s}}\right)} \approx-\frac{B_{\tau}}{(\delta+r) \Delta t_{s s}}
$$

Combining (7) with (11), the short-run elasticities of taxable and exempt spending are

$$
\varepsilon_{s_{i, t_{s s-1}}} \equiv \frac{d \ln \left(s_{i, t_{s s}} / s_{i, t_{s s-1}}\right)}{d \ln \left(1+\tau_{t_{s s}}\right)} \approx \varepsilon_{\Delta t_{s s-1}}+\varepsilon_{c_{i}}
$$

and the long-run spending elasticities are well approximated by the corresponding consumption 
elasticities,

$$
\varepsilon_{s_{i, \infty}} \equiv \frac{d \ln \left(s_{i, t_{s s}} / s_{i, t_{s s-q}}\right)}{d \ln \left(1+\tau_{t_{s s}}\right)} \approx \varepsilon_{c_{i}}
$$

for $q \geq 2$.

Calibration and Aggregation We calibrate the model to match steady state values, the long-run responses, and one short-run elasticity: the fall of taxable spending in the month of the tax increase relative to steady state. We then assess the model along two dimensions. First, we analyze whether the model can generate the short-run spending dynamics for both taxable and tax-exempt goods shown in the left panel of Figure 3. Second, while matching the short-run dynamics is an important test for the model to pass, it does not tell us whether the magnitudes of the observed responses are economically reasonable. To answer this question, we calculate the revealed reservation wage implied in the shopping fixed costs necessary to match the short-run spending dynamics.

The long-run response of tax-exempt spending is close to zero as seen in Figure 3. Looking at equations (10) and (13), this implies that intertemporal and intratemporal consumption substitution elasticities $\sigma$ and $\eta$ must be of similar size. To assess whether both are small or large, we calculate the relative difference between the long-run spending elasticities of taxable and tax-exempt, which equals the intratemporal consumption elasticity. The estimated difference is small and hence we set both elasticities to 0.29 , although this estimate is not statistically different from zero (standard error of 0.48 ).

The two remaining parameters calibrated to steady state values are the share parameters $b_{i}$ and the steady-state transaction interval $\Delta t_{s s}$. The share parameters are set to match the average expenditure shares of taxable and tax-exempt goods in months without sales tax changes: 0.55 and 0.45 , respectively. We set the steady state interval to 0.27 months, corresponding to the sample average of 8.3 days between two shopping trips. The effective annual risk-free rate is $3 \%$ and the depreciation rate is set such that the steady state equation (9) holds. Relative pre-tax prices are normalized to one.

Before calibrating the remaining parameter $\kappa$ to match the decline in taxable spending in the month of the tax increase, we need to adjust for the fact that model time is measured at trips frequency rather than monthly frequency (which did not matter for steady state calibrations). To eliminate artificial lumpiness resulting from the allocation of trips to months, ${ }^{29}$ we distribute shopping start dates of a unit mass of otherwise identical consumers uniformly on an interval that starts at date 0 and has length $\Delta t_{s s-2} \cdot{ }^{30}$ We can then aggregate per trip quantities $s_{i, t_{n}}$

\footnotetext{
${ }^{29}$ To see the issue arising from time aggregation of a single consumer, suppose that $\Delta t_{s s}=\Delta t_{s s-2}=0.25$, which holds approximately in the data, but $\Delta t_{s s-1}=\Delta t_{s s}+\varepsilon$ for an arbitrarily small $\varepsilon>0$ due to additional stockpiling. This consumer would therefore only make 3 trips in month -1 but 4 trips in any other month, which would lead to very large monthly spending changes even though spending per trip in the continuous-time model would increase only very little on trip $t_{s s-1}$ relative to all other trips (i.e., $s_{i, t_{s s-1}} \approx s_{i, t_{n}} \forall t_{n} \neq t_{s s-1}$ ).

${ }^{30}$ Equivalently, we could endow consumers with different inventory levels at date 0 .
} 
(valued at pre-tax prices normalized to 1) to monthly spending quantities $s_{i, t}$, where $t$ measures event time, as follows:

$$
\begin{aligned}
s_{i,-2} & =\frac{s_{i, t_{s s-2}}}{\Delta t_{s s-2}} \\
s_{i,-1} & =\left(1-\Delta t_{s s-2}\right) \frac{s_{i, t_{s s-2}}}{\Delta t_{s s-2}}+s_{i, t_{s s-1}} \\
s_{i, 0} & =\left[1-\left(\Delta t_{s s-1}-\Delta t_{s s-2}\right)\right] \frac{s_{i, t_{s s}}}{\Delta t_{s s}} \\
s_{i, 1} & =\frac{s_{i, t_{s s}}}{\Delta t_{s s}} .
\end{aligned}
$$

In month -1 , the rate of spending over the initial fraction $\left(1-\Delta t_{s s-2}\right)$ of the month is $s_{i, t_{s s-2}} / \Delta t_{s s-2}$ (spending per trip $s_{i, t_{s s-2}}$ times shopping frequency $1 / \Delta t_{s s-2}$ ). The rate of spending over the remaining fraction $\Delta t_{s s-2}$ of the month is $s_{i, t_{s-1}} / \Delta t_{s s-2}$. In month 0 , the rate of spending is initially 0 on an interval of length $\Delta t_{s s-1}-\Delta t_{s s-2}$ because each household stocked up more on interim shopping trip $t_{s s-1}$ in month -1 . The spending rate on the remaining fraction of month 0 is $s_{i, t_{s s}} / \Delta t_{s s} .^{31}$

With this aggregation, setting $\kappa=\$ 5.2$ matches the decline of $1.45 \%$ in taxable spending in the month of the tax increase relative to the steady state (left panel of Figure 3). These fixed costs per trip enter the model solution as a fraction of total spending per trip, which we set to its sample average of $P_{t_{s s}} S_{t_{s s}}=\$ 83 .^{32}$

Model Evaluation The right panel of Figure 3 shows that the model is successful in producing the short-run spending patterns surrounding a 1 percentage point sales tax increase, both qualitatively and quantitatively. The simple model fits the data well even though it only uses three data points for the calibration (the long-run spending changes of 0 and -0.29 and the short-run deviation of taxable spending from the steady state of -1.45).

We assess the economic magnitude of these responses using auxiliary data from the American Time Use Survey (ATUS) to calculate the reservation wage implied in the estimated fixed costs. Across our sample period, people in the ATUS report spending on average 0.1 hours per day on grocery shopping. The average and median number of days between two trips to a grocery store by consumers in the Nielsen data are 6 and 4, respectively, implying about half an hour spent in the grocery store per trip. Hamrick and Hopkins (2012) estimate that the average respondent spends another 15 minutes on travel per grocery shopping trip. These estimates result in an

\footnotetext{
${ }^{31}$ Technically, starting with a unit mass of consumers that have completely unsynchronized shopping cycles, a systematic change in long-run shopping intervals $\Delta t_{s s}$ relative to $\Delta t_{s s-2}$ in response to a sales tax increase introduces small echo effects in aggregate monthly steady state spending either due to a recurring hole in the distribution of shoppers over a small interval of length $\left|\Delta t_{s s-2}-\Delta t_{s s}\right|$ or a small amount of excess mass (bunching) over an interval with the same length. However, this difference is very small in practice such that our aggregation procedure yields a very good approximation of average monthly spending dynamics.

${ }^{32}$ We exclude small transactions from this calculation in order to identify shopping trips rather than say lunch purchases for immediate consumption for example, which are not captured by the model.
} 
economically reasonable range for the reservation wage between $\$ 7$ and $\$ 10.5 .^{33}$

\section{Shopping Complementarity}

The reduced-form response of tax-exempt spending in Section 4.4 is consistent either with non-salience of tax-exemption status (i.e., consumer confusion about which goods are exempt) or with complementarities between taxable and tax-exempt spending arising from the short-run shopping cost savings achieved by also stockpiling tax-exempt goods while shopping for taxable goods before the tax increase. For instance, on a typical trip to a grocery store, a household may purchase both exempt and non-exempt goods (fresh produce, cookware, a bottle of aspirin, and a deli sandwich, for example). If households adjust purchasing responses to sales tax changes at a trip level, then we may expect that behavior of exempt and non-exempt goods would be correlated. Moreover, households with heterogeneous shopping costs would be predicted to have different spending responses for exempt goods.

In this section, we provide evidence for the role of shopping trip complementarities in explaining the observed patterns. We document this novel mechanism along three dimensions, taking advantage of the detailed information on consumer and retailer locations. First, we exploit heterogeneity in "revealed costs" of shopping across consumers, reflected in the consumer's average shopping frequency in the sample. Consumers that shop infrequently in the absence of a tax change reveal that they face higher shopping costs than frequent shoppers and hence should increase tax-exempt spending relatively more. This may reflect both higher reservation wages as well as higher direct costs like gasoline or public transit fees. Second, we test the extent to which the exempt spending response depends on the degree to which consumers can bundle their exempt and non-exempt spending. Intuitively, consumers that shop at stores that sell solely exempt or solely taxable goods should have lower exempt spending responses, while consumers that typically shop at stores selling a mix of taxable and exempt goods should have higher exempt spending responses. Finally, we implement a form of a placebo test by looking at the relative response of taxable and tax-exempt online spending, since shopping complementarities are likely absent or minimal when shopping online.

Table 5 presents the results of this analysis. Panel A investigates whether households with different 'revealed shopping costs' behave differently following a change in sales taxes. We first calculate the average number of shopping trips they make in a month for each household. We then assign the top $25 \%$ of households (with more than 19 trips per month) as 'low-shopping-cost' households and the bottom $25 \%$ of households (with fewer than 9 trips per month) as the 'highshopping-cost' households. We propose that the average number of shopping trips a household takes per month correlates negatively with the total costs of the trip, including transportation costs, inventory costs, and time costs, in line with the model in Section 5 .

Columns 1 and 2 estimate the spending response of exempt and taxable goods for households

\footnotetext{
${ }^{33}$ Note that this reservation wage is after taxes, i.e., after income and payroll taxes.
} 
with low shopping costs following a sales tax increase. We find no impact on exempt spending, while taxable spending declines $2.2 \%$. In contrast, for households we deem to be high-cost shoppers, both exempt and taxable spending fall nearly identically, suggesting that these households bundle their purchases to minimize the number of shopping trips that they must undertake.

Panel B examines the response of exempt spending across two different types of households. Using the granular Nielsen purchase data, we determine how skewed a given household's average shopping trip is towards either exempt or taxable purchasing:

$$
\text { Trip Complementarity } \text { Co }_{i}=1-\frac{\sum_{j}\left|\left(T_{i j}-0.5\right)\right| \times 2}{\sum_{j} \mathbf{1}} \text {. }
$$

That is, if all of household $i$ 's trips (indexed by $j$ ) are for $100 \%$ taxable $\left(T_{i j}=1\right.$ ) or $100 \%$ exempt goods $\left(T_{i j}=1\right)$, his average trip complementarity measure would receive a value of 0 . If each trip was composed of $50 \%$ taxable goods and $50 \%$ exempt goods $\left(T_{i j}=0.5\right)$, the measure would take on a value of 1 .

In Column 5, we look at the highest quartile of households along this measure. We find that exempt spending for this group responds strongly to changes in sales taxes. In contrast, the quartile of households whose taxable and exempt spending is conducted at largely different stores sees a much smaller (and insignificant) change in spending on exempt goods shown in Column 6 .

Finally, Panel C tests for the asymmetric response of online spending and mail order purchases to sales tax changes as predicted by models with shopping trip costs. When shopping online, there are fewer gains to bundling multiple purchases at once, since no transportation costs need be incurred across different websites and online purchases are often made of single goods rather than a cart full of goods. Just as with the low-cost shoppers, we find that, following an increase in sales taxes, spending on exempt goods from online merchants is largely unaffected (Column 7), while spending on taxable goods increases significantly (Column 8). This response suggests that consumers evade sales taxes by substituting to online platforms and failing to pay use taxes on those purchases.

Identification of Demand in the Presence of Shopping Complementarities Overall, these results suggest that shopping complementarities play an important role in affecting the purchasing decisions of households. It also demonstrates the caution one must take when estimating price elasticities in a difference-in-differences framework, even in the absence of general equilibrium effects. Despite the fact that some goods' prices are unaffected, demand for them may shift due to changes in shopping behavior. This is true in our setting with tax changes, but also may be true when stores put portions of their goods on sale, or an appreciable number of items at a store undergo a price change at the same time. 


\section{Long-Run Responses to Persistent Tax Incentives}

Section 4 has shown that intertemporal substitution is only a temporary response and spending quickly reverts back to pre-change levels. In the model, this happens because the intertemporal consumption substitution elasticity and the intratemporal substitution elasticity between taxable to tax-exempt products are both low. An alternative explanation of the small long-run responses is that it might instead reflect learning-and-forgetting dynamics, i.e., consumers forgetting about sales tax rates over time. We test this explanation by analyzing the spending response to changes in tax incentives that can be exploited more persistently. Specifically, we first test whether consumers who can shop in another tax jurisdiction with lower rates increasingly do so after a sales tax increase in their home ZIP code, and whether this response persists in the long run. We then extend our analysis of online shopping in Section 6 to test whether the effect of a sales tax increase on online spending is also persistent. Table 6 presents the results from this analysis.

While our empirical approach is the first to leverage highly-local changes in sales taxes in this setting, we are far from the first to approach the question of how cross-border and online spending reacts to differences in sales tax rates. Previous work has thoroughly analyzed some these impacts across a range of goods and empirical specifications (e.g., Goolsbee (2000), Agrawal (2015), and the other studies cited in the introduction). We see our own estimates of cross-border and online tax avoidance as pushing this literature further and placing these results into a broader context of household tax avoidance across several avoidance channels.

Jurisdictional Tax Avoidance: 'Cross-Border' Shopping One way to avoid paying more sales taxes is by engaging in cross-border shopping, taking advantage of lower rates in neighboring tax jurisdictions. To analyze this mechanism, we leverage one benefit of the Nielsen Consumer Panel, its ability to observe details of the shopping trips that households took including the type and location of a retailer. The NCP identifies stores by their three-digit ZIP code. In conjunction with the location of the household, this allows us to determine what fraction of household spending was conducted in an 'alternative' three-digit ZIP code or state (outside one's 'home' ZIP code or state).

Panel A analyzes such cross-border shopping behavior. Column 1 tests whether this ratio responds to changes in local sales taxes, finding no significant effect. However, it is generally difficult for most households to switch to shopping in a different three-digit ZIP code given that the average three-digit ZIP code spans over 1,000 square miles. So, we might expect that households who are already able to conduct such shopping trips (e.g., those who might live or commute near a state or three-digit ZIP code boundary) might be more sensitive along this margin. In order to test this, we estimate (1) by regressing the fraction of a household's total spending in an alternative three-digit ZIP code outside its own home ZIP code (i.e., residential five-digit ZIP code) on log-changes in the gross sales tax rate interacted with the average alternative three-digit 
ZIP spending over all household-months. Column 2 shows precisely this mechanism, a significant increase in alternative-ZIP spending in the month of the tax change for households who had already been conducting some of their shopping in alternative three-digit ZIP codes. Columns 3 and 4 show the same pattern for purchases across state lines, which are less common (average spending share of less than $2 \%$ compared to the $8 \%$ spending share in alternative three-digit ZIP codes). This signals that, for households who could conceivably substitute spending into a different tax jurisdiction, an increase in the sales tax in their residential tax jurisdiction makes them shift additional spending to that alternative tax jurisdiction.

The short-run month-to-month behavior is estimated only imprecisely and the interaction terms are not statistically significant. One reason is that in contrast to the significant intertemporal substitution of short-run spending shown in Section 4, consumers should rationally only increase cross-border spending after sales taxes have increased in their home ZIP code, not before. Since most products in the Nielsen data are fairly storable or durable, the next cross-border shopping trip might be months away such that this adjustment occurs only gradually over time. Columns 5 and 6 show that the long-run response is indeed larger and more precisely estimated. The interaction effects are now two to three times larger than in the short-run and statistically significant.

An important note about substitution across jurisdictions is that while this pattern of behavior is evidence for strong impacts of sales tax changes on spending behavior, actual household consumption is affected to a much smaller degree. A recent study by Davis, Knoepfle, Sun and Yannelis (2016) also looks at the geographical substitution patterns surrounding sales taxes. Using credit card spending data to examine how ZIP code level spending is impacted by changes in sales taxes on both sides of the border of the tax jurisdiction, they estimate an elasticity of approximately 4.2 in ZIP codes that are located on state borders. Our results here align with their own. They also note persistent substitution to online retailers following sales tax increases, another persistent adjustment margin to which we turn next.

Use Tax Evasion: Online Shopping Another potential way for households to avoid increases in sales taxes is to shop online or via catalog and mail order (hereafter just referred to as 'online spending' or 'online merchants'). Online merchants are generally not required to collect sales taxes if the merchant does not maintain a physical presence in the same state as the purchaser. During our sample period, most online purchases were done without purchasers paying sales tax. Instead, households are officially required to pay a 'use tax' to their home state when completing their annual taxes. However, compliance with the use tax is extremely low. For instance, as mentioned before only $0.3 \%$ of California tax returns reported any use tax related purchases in 2009. Because of this, households may shift purchases online where possible when sales taxes increase.

Fortunately, the Nielsen Consumer Panel data categorizes purchases made from online merchants separately from brick-and-mortar retailers. Panel B shows the result of this analysis. We 
find that household shift spending to these online merchants in the month following a sales tax increase (Column 7) and this substitution persists in the long run (Column 8). ${ }^{34}$

These coefficients suggest that online spending by an affected household increases $1.6 \%$ following an increase in the sales tax rate of 1 percentage point. Our estimates are consistent with recent estimates of the effect of taxation on online commerce. For instance, using state sales tax rate changes and purchase data from eBay, Einav, Knoepfle, Levin and Sundaresan (2014) find an online-offline substitution elasticity of 1.8, which is in line with our estimate of 1.6. Similarly, Baugh, Ben-David and Park (2015) estimate a tax elasticity of online purchases of -1.1 using Amazon's staggered introduction of sales tax collection across different states in different months. This estimate is consistent with the ones reported above given that their experiment is a relative increase in the taxation of online purchases, while the previous experiments are relative decreases in the taxation of online purchases, i.e., an increase in the taxation of purchases from brick-and-mortar stores.

\section{Discussion and Conclusions}

From 2004 to 2014, there were more than 2,000 changes in state and local tax rates in the United States. Understanding how households respond to tax changes has important implications both for optimal taxation and for the effectiveness of consumption taxes as a tool to stimulate the economy.

Our analysis speaks to the efficiency of taxation in the long run and the effectiveness of sales taxes in stimulating the economy in the short run. Since many consumers are forward-looking, they strongly respond in the short run by stocking up on storable and durable consumer goods. This intertemporal spending elasticity and, hence, the stimulative effect of the tax change, is larger for more durable and storable goods. At the same time, we find that this effect is relatively short lived, which implies a small intertemporal consumption elasticity. This small long-run effect, while imprecisely estimated, would suggest that sales taxes are also a relatively efficient form of taxation.

We also find that households are on average aware of other methods to avoid sales taxes, engaging in geographical arbitrage by increasing trips to locations with a lower sales tax rate after a tax increase in their home ZIP code and increasing the amount of purchases made from online merchants. These additional adjustment margins also affect the long-run efficiency of sales taxes and the short-run effectiveness of sales taxes as a macroeconomic stabilization tool. On the one hand, tax leakage (cross-border or online shopping) increases the responsiveness of demand in the short run and thus enhances the stimulus effect. On the other hand, tax leakage also reduces the long-run efficiency of the tax by increasing deadweight losses. However, we show that the aggregate effect of these leakages is quantitatively small.

Our estimates mainly capture intertemporal substitution of spending. The effectiveness of

\footnotetext{
${ }^{34}$ We also find positive effects when looking at the fraction of spending done online rather than the change in dollar amounts.
} 
sales tax changes as a macroeconomic stimulus tool also depends on income and wealth effects, which are difficult to identify in our setting because we are unable to identify the exact date at which households become aware of the upcoming tax changes (see Figure 2). ${ }^{35}$ However, a sales tax stimulus program could be designed to be revenue neutral, either over the business cycle or by having compensating income tax changes such as the Japanese VAT change in 1997; see e.g. Cashin (2017).

Surprisingly, we find that tax-exempt spending is affected to much the same degree as spending on taxable goods in the periods surrounding sales tax changes. To explain this seemingly irrational behavior, we build and calibrate a model of inventory and shopping complementarities where households rationally bundle purchases of different types of goods into single shopping trips. We show that this shopping complementarity mechanism has support in the data, with households possessing lower revealed shopping costs tend to bundle purchases less than households with higher costs.

Finally, our analysis suggests that the spending response to foreseeable sales tax changes might be very different than to unexpected posted price changes. This has potentially important implications both for tax incidence analysis but also more generally for structural models of consumer demand.

\section{References}

Agarwal, Sumit, John C. Driscoll, Xavier Gabaix, and David Laibson. 2013. "Learning in the Credit Card Market." Working Paper.

Agarwal, Sumit, Nathan Marwell, and Leslie McGranahan. 2017. "Consumption Responses to Temporary Tax Incentives: Evidence from State Sales Tax Holidays." American Economic Journal: Economic Policy.

Agrawal, David R. 2015. "The Tax Gradient: Spatial Aspects of Fiscal Competition." American Economic Journal: Economic Policy, 7(2): 1-29.

Baugh, Brian, Itzhak Ben-David, and Hoonsuk Park. 2015. "The 'Amazon Tax': Empirical Evidence from Amazon and Main Street Retailers." Working Paper.

Broda, Christian, and David E. Weinstein. 2010. "Product Creation and Destruction: Evidence and Price Implications." American Economic Review, 100(3): 691-723.

Cabral, Marika, and Caroline Hoxby. 2013. "The Hated Property Tax: Salience, Tax Rates, and Tax Revolts." Working Paper.

Cashin, David. 2014. "The Intertemporal Substitution and Income Effects of a Consumption Tax Rate Increase: Evidence from New Zealand." Working Paper.

Cashin, David. 2017. "The Household Expenditure Response to a Consumption Tax Increase." Working Paper.

Cashin, David, and Takashi Unayama. 2016. "Measuring Intertemporal Substitution in Consumption: Evidence from a VAT Increase in Japan." Review of Economics and Statistics, 98(2): 285-297.

Chen, Xiu, Harry M. Kaiser, and Bradley J. Rickard. 2014. "The Salience of Excise vs. Sales Taxes on Healthy Eating: An Experimental Study." Working Paper.

Chetty, Raj, Adam Looney, and Kory Kroft. 2009. "Salience and Taxation: Theory and Evidence." American Economic Review, 99(4): 1145-1177.

\footnotetext{
${ }^{35}$ In Appendix $\mathrm{C}$ we discuss some evidence for income effects for a subset of sales tax changes for which we know the date in which they are approved. Two other factors that affect the effectiveness of the stimulus are the fraction of liquidity constrained households and the price response of retailers. While our data does not measure liquid assets directly, we see slightly larger responses among higher-income consumers. Similarly, while retail prices in our data do not substantially respond to the sales tax changes (see Table 3), this could change if sales taxes are used systematically as a counter-cyclical policy tool.
} 
Coglianese, John, Lucas W. Davis, Lutz Kilian, and James H. Stock. 2017. "Anticipation, Tax Avoidance, and the Price Elasticity of Gasoline Demand." Journal of Applied Econometrics, 32(1): 1-15.

Correia, Isabel, Emmanuel Farhi, Juan Pablo Nicolini, and Pedro Teles. 2013. "Unconventional fiscal policy at the zero bound." American Economic Review, 103(4): 1172-1211.

Crossley, Thomas F., Hamish W. Low, and Cath Sleeman. 2014. "Using a Temporary Indirect Tax Cut as a Fiscal Stimulus: Evidence from the UK." Working Paper.

D’Acunto, Francesco, Daniel Hoang, and Michael Weber. 2017. "The Effect of Unconventional Fiscal Policy on Consumption Expenditure." Working Paper.

Davis, Trevor, Dan Knoepfle, Stephen Sun, and Constantine Yannelis. 2016. "Greener on the Other Side: Estimating Consumer Sensitivity to Local Sales Tax Changes." Working Paper.

DeCicca, Philip, Donald Kenkel, and Feng Liu. 2013. "Who Pays Cigarette Taxes? The Impact of Consumer Price Search." Review of Economics and Statistics, 95(2): 516-529.

Einav, Liran, Dan Knoepfle, Jonathan Levin, and Neel Sundaresan. 2014. "Sales Taxes and Internet Commerce." American Economic Review, 104(1): 1-26.

Einav, Liran, Ephraim Leibtag, and Aviv Nevo. 2010. "Recording Discrepancies in Nielsen Homescan Data: Are they Present and Do They Matter?" QME, 8(2): 207-239.

Farhi, Emmanuel, and Xavier Gabaix. 2017. "Optimal Taxation with Behavioral Agents." Working Paper.

Feldman, Naomi E., and Bradley J. Ruffle. 2015. "The Impact of Including, Adding, and Subtracting a Tax on Demand." American Economic Journal: Economic Policy, 7(1): 95-118.

Fernández-Villaverde, Jesús, and Dirk Krueger. 2001. "Consumption and Saving over the Life Cycle: How Important are Consumer Durables?" Working Paper.

Finkelstein, Amy. 2009. "EZTax: Tax Salience and Tax Rates." Quarterly Journal of Economics.

Gabaix, Xavier. 2014. "A Sparsity-Based Model of Bounded Rationality." Quarterly Journal of Economics, 129(4): 1661-1710.

Gabaix, Xavier. 2016. "Behavioral Macroeconomics Via Sparse Dynamic Programming." Working Paper.

Goolsbee, Austan. 2000. "In a World without Borders: The Impact of Taxes on Internet Commerce." Quarterly Journal of Economics, 115(2): 561-576.

Goolsbee, Austan, Michael F. Lovenheim, and Joel Slemrod. 2010. "Playing with Fire: Cigarettes, Taxes, and Competition from the Internet." American Economic Journal: Economic Policy, 2(1): 131-54.

Hamrick, Karen S., and David Hopkins. 2012. "The time cost of access to food-Distance to the grocery store as measured in minutes." International Journal of Time Use Research, 9(1): 28-58.

Hendel, Igal, and Aviv Nevo. 2006a. "Measuring the Implications of Sales and Consumer Inventory Behavior." Econometrica, 74(6): 1637-1673.

Hendel, Igal, and Aviv Nevo. 2006b. "Sales and Consumer Inventory." RAND Journal of Economics, 37(3): 543-561.

Hendel, Igal, and Aviv Nevo. 2013. "Intertemporal Price Discrimination in Storable Goods Markets." American Economic Review, 103(7): 2722-2751.

Howitt, Peter. 1977. "Intertemporal Utility Maximization and the Timing of Transactions." American Economic Review, 67(2): 156-165.

Keynes, John Maynard. 1936. The General Theory of Employment, Interest and Money.: Macmillan Cambridge University Press.

Mian, Atif, and Amir Sufi. 2012. "The Effects of Fiscal Stimulus: Evidence from the 2009 Cash for Clunkers Program." Quarterly Journal of Economics, 127(3): 1107-1142.

Nakamura, Emi, and Jón Steinsson. 2017. "Identification in Macroeconomics." Working Paper.

Nakamura, Emi, and Jón Steinsson. 2018. "High Frequency Identification of Monetary Non-Neutrality: The Information Effect." Working Paper.

Ogaki, Masao, and Carmen M. Reinhart. 1998. "Measuring Intertemporal Substitution: The Role of Durable Goods." Journal of Political Economy, 106(5): 1078-1098.

Stephens-Davidowitz, Seth. 2013. "The Cost of Racial Animus on a Black Presidential Candidate: Evidence Using Google Search Data." Working Paper.

Walsh, Michael J., and Jonathan D. Jones. 1988. "More Evidence on the "Border Tax" Effect: The Case of West Virginia, 1979-84." National Tax Journal, 41(2): 261-265. 
Figure 1: ZIP Code Level Sales Tax Rates

(a) Sales tax rates

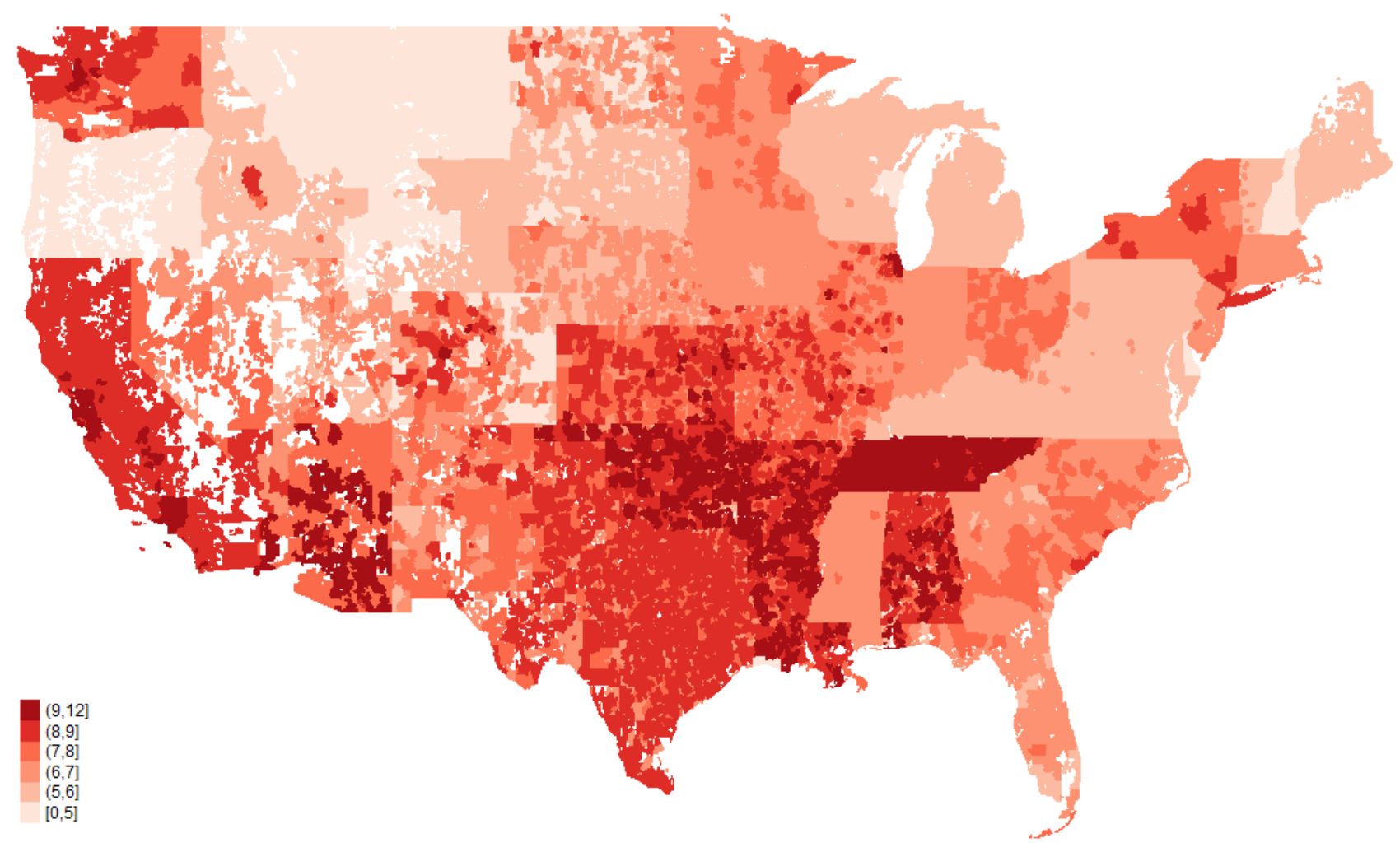

(b) Tax rate changes, 2008-14

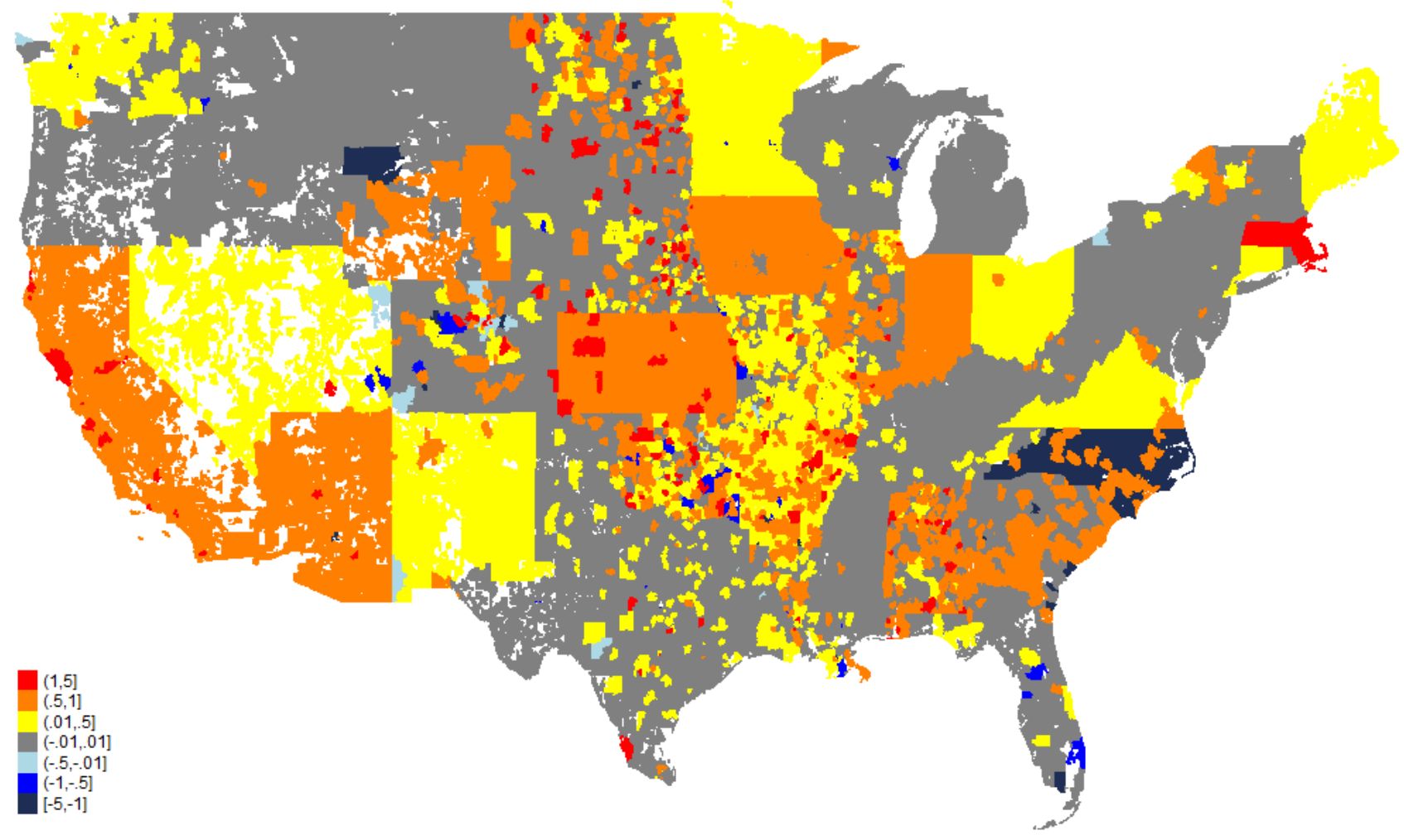

Notes: Maps plot the maximum level (a) respectively change (b) of total sales tax rates in each five-digit ZIP code for years 2008-14, matching the sample period of the Nielsen Consumer Panel. Sales tax rates are expressed in percentages. Total sales tax rate changes may be driven by changes in state, city, county, or special district sales tax rates. White ZIP codes have missing sales tax rates or are not covered by Nielsen. 
Figure 2: Response of Newspaper Coverage and Google Searches to State Tax Changes

(a) News article ratio around state sales tax rate changes (in \%)

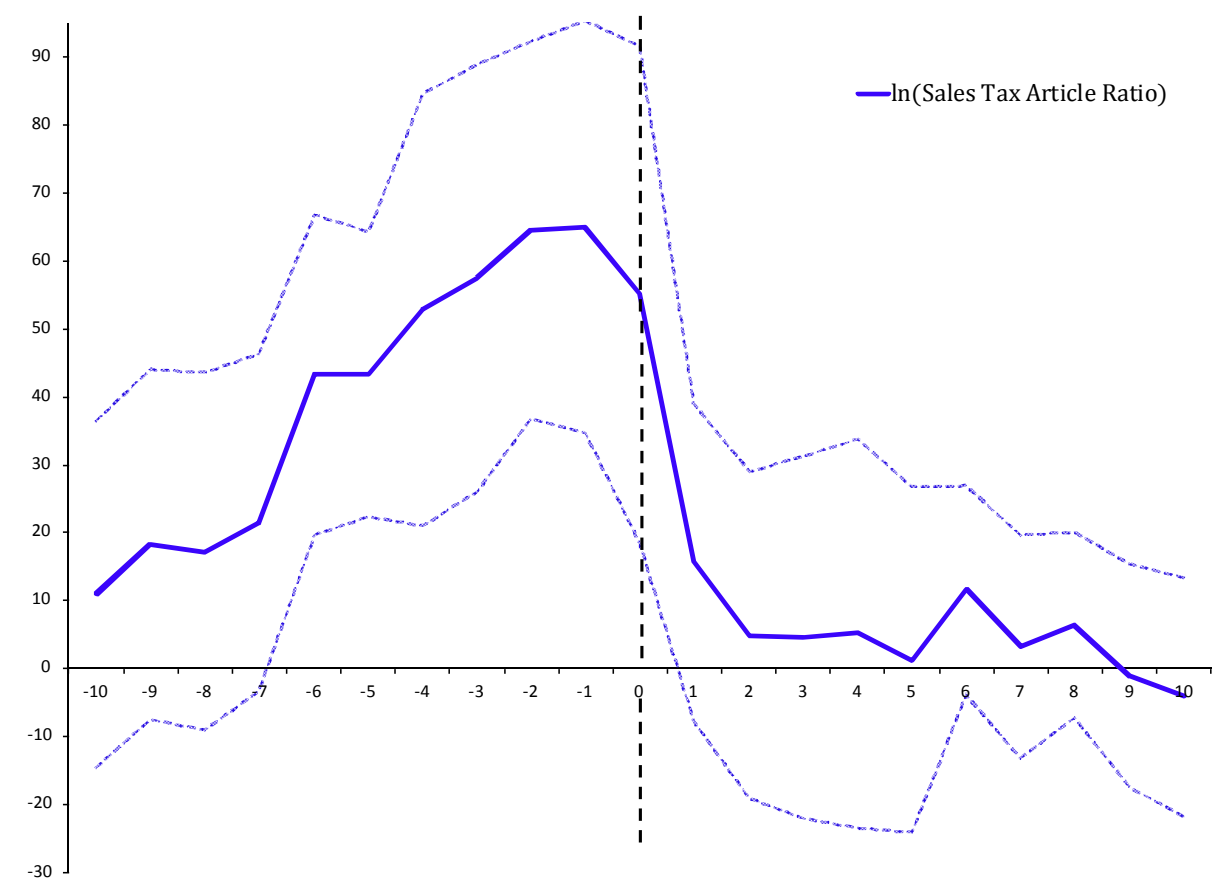

(b) Google Search around state sales tax rate changes (in \%)

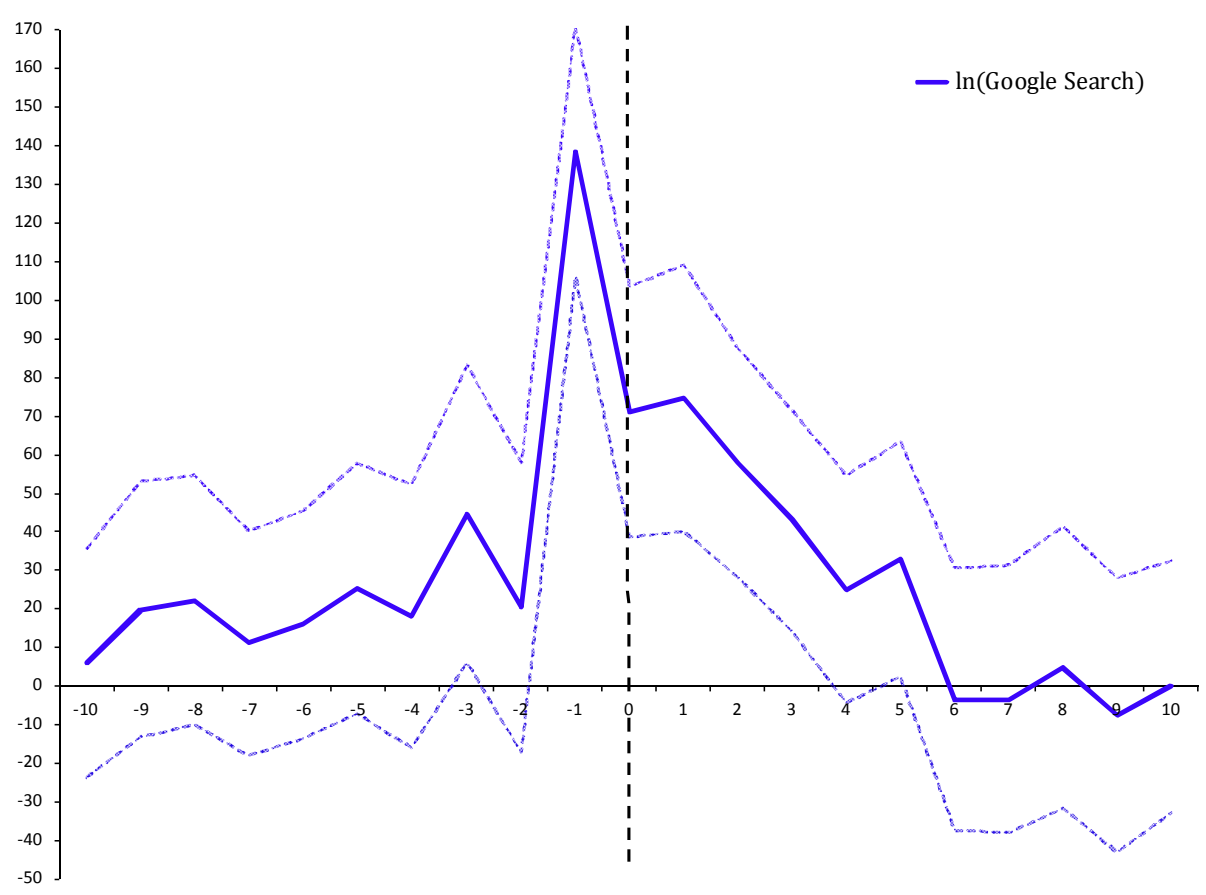

Notes: Top panel plots coefficients from a regression of the ratio of news articles that contain the term 'sales tax' or 'sales taxes' as a fraction of all newspaper articles in a given month across newspapers in that state. Y-axis units are percentage points. News articles taken from Access World News and cover approximately 3,000 US newspapers ranging from large national papers to local papers. Bottom panel plots coefficients from a regression of logged Google search activity from Google Trends. Y-axis units are percentage deviations from baseline. Household and period fixed effects are included. Standard errors clustered by state. Red vertical lines denote 'time 0', where a state level sales tax rate change occurs. 


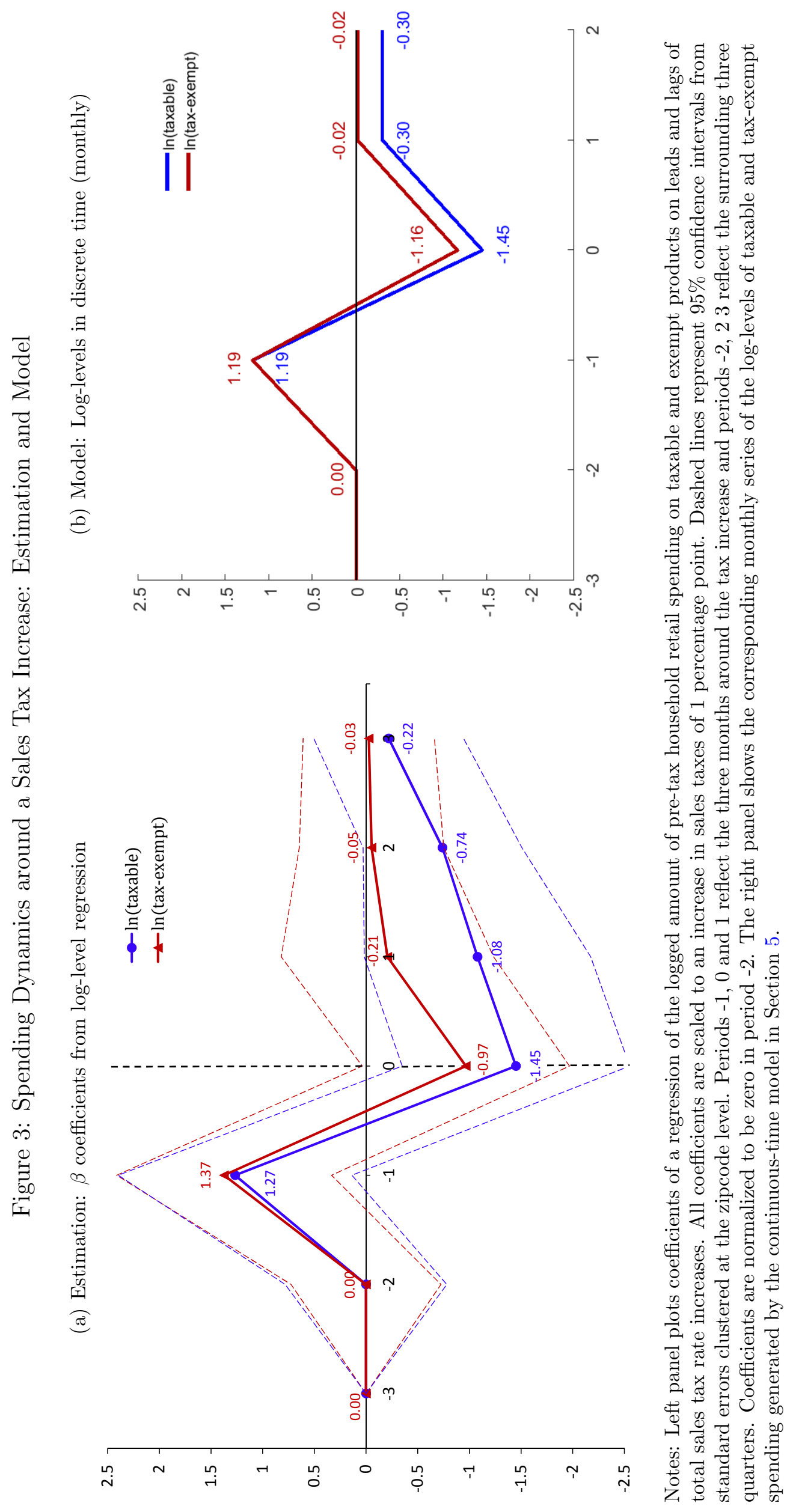


Figure 4: Continuous-Time Model Dynamics around a Sales Tax Increase

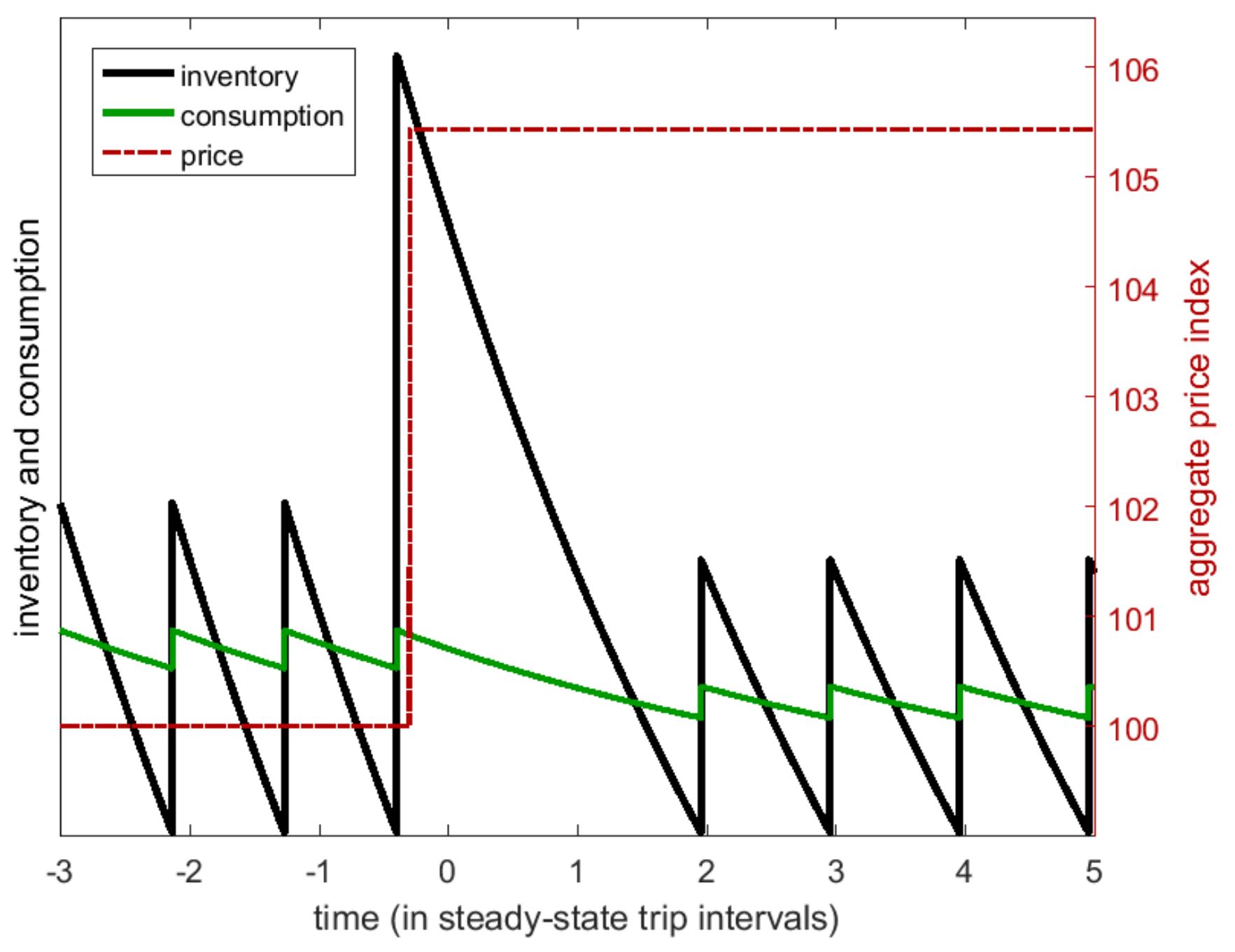

Notes: Figure plots the evolution of inventory $S(t)$ and consumption $C(t)$ of the composite good and the taxinclusive aggregate price index $P(t)$ around a sales tax increase. To make this example as stark as possible, we use a very large tax change of 10 percentage points and an unrealistically large intertemporal consumption substitution elasticity of $\sigma=6$ and a low fixed cost of $\kappa=2$. Otherwise, the model parameters are set as described in Section 5. 
Table 1: Response of Taxable Spending and Shopping Frequency to a Sales Tax Increase

Data source:

Dependent variable: log change of monthly taxable retail spending (Panels $\mathrm{A}$ and

B).
Nielsen Consumer Panel (NCP)

\begin{tabular}{llc}
\multicolumn{3}{c}{ A. Main Analysis } \\
\hline Baseline & $\begin{array}{l}\text { State tax } \\
\text { rate only }\end{array}$ & $\begin{array}{c}\text { Sales tax } \\
\text { cuts }\end{array}$
\end{tabular}

B. Robustness

\begin{tabular}{ccccc}
\hline $\begin{array}{c}\text { Household } \\
\text { charac. }\end{array}$ & Business & Drop Great & State-period & No online \\
cycle & Recession & FE & spending
\end{tabular}

$(4)$

(5) $-(6)$

$-1.719^{*}$

$-2.034^{* * *}$

(0.648)

$-2.082^{* * *}$

(0.648)

$-2.012^{* *}$

(0.882)

$(0.701)$

$(0.965)$

$-2.185^{* *}$

(1.031)

Period FE

Household FE

Household characteristics

Local unemployment rate

State-period FE

Observations

Yes Yes Yes

Yes Yes Yes

Yes

$\begin{array}{ll}\text { Yes } & \text { Yes } \\ \text { Yes } & \text { Yes } \\ & \text { Yes }\end{array}$

Yes

Yes

R-squared

$4,137,927$

$5,928,468$

$4,114,413$

$4,137,927$

0.014

0.014

Nielsen Retailer Panel (NRP)

Nielsen Consumer Panel (NCP)

Data source:

C. Store Sales

Dependent variables:

log change of monthly taxable retail sales (Panel $\mathrm{C}$ ) and the number of monthly store visits (Panle D).

B. cont. C. Store Sales

No border shopping

\begin{tabular}{ccc}
\multicolumn{3}{c}{ C. Store Sales } \\
\hline Baseline & $\begin{array}{c}\text { Business } \\
\text { cycle }\end{array}$ & State-period \\
& FE
\end{tabular}

FE

(11) (12)

(10)

$-2.814^{* *}$

$-2.794^{* *}$

(1.368)

$-3.265^{* *}$

(1.440)

Yes

Yes

Yes

Yes

Yes

Household characteristics

Local unemployment rate

State-period FE

Store FE

Observations

Yes

R-squared

$2,926,272$

Yes

Yes

Yes

0.024

$2,461,491$

$2,461,491$

0.140

0.140

Yes
Yes

Yes
Yes

Yes

Yes

Yes

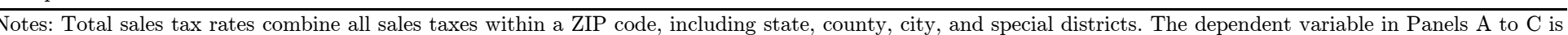

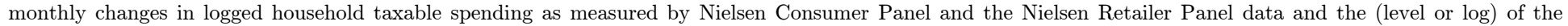

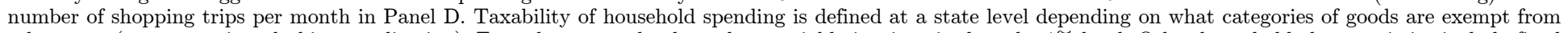

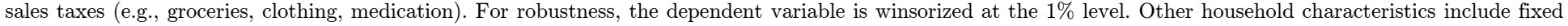

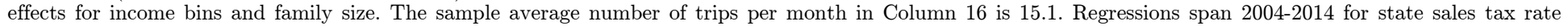

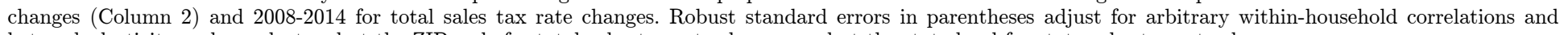
heteroskedasticity and are clustered at the ZIP code for total sales tax rate changes and at the state level for state sales tax rate changes. 
Table 2: Storability and Intertemporal Substitution

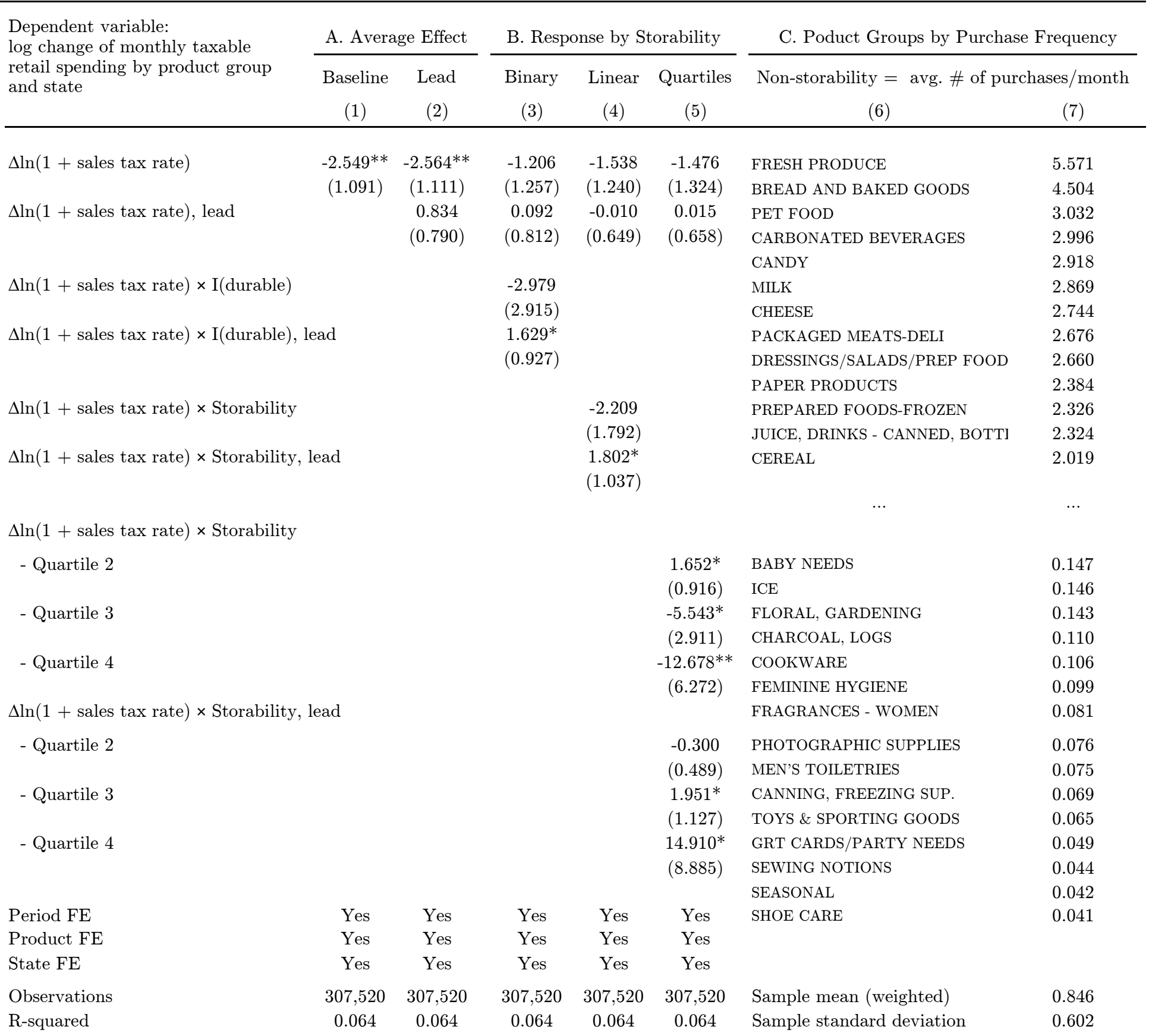

Notes: The dependent variable is the monthly log change in taxable retail spending by product group and state across all households in the Nielsen Consumer Panel, 2004-2014. The main independent variable is changes in state sales tax rates. We drop "magnet data", leaving 53 unique product groups. All regressions are estimated using least squares weighted by average sales per product group. Robust standard errors in parentheses are clustered at the state level. 
Table 3: Quantity and Price Response

A. Quantity Response

B. Price Response

\begin{tabular}{|c|c|c|c|c|c|c|c|c|}
\hline \multirow{3}{*}{ Dependent variable: } & \multirow{3}{*}{$\begin{array}{c}\Delta \ln (\text { taxable }) \\
(1)\end{array}$} & \multirow{3}{*}{$\begin{array}{c}\Delta \ln (\text { exempt }) \\
(2)\end{array}$} & \multirow{3}{*}{$\begin{array}{c}\Delta \ln (\text { taxable }) \\
(3)\end{array}$} & \multirow{3}{*}{$\begin{array}{c}\Delta \ln (\text { exempt }) \\
(4)\end{array}$} & \multirow{2}{*}{\multicolumn{2}{|c|}{$\Delta \ln ($ retail price $)$}} & \multirow{2}{*}{\multicolumn{2}{|c|}{$\Delta \ln ($ wholesale price $)$}} \\
\hline & & & & & & & & \\
\hline & & & & & (5) & (6) & $(7)$ & $(8)$ \\
\hline$\Delta \ln (1+$ total sales tax rate $)$ & $\begin{array}{c}-2.330^{* * *} \\
(0.479)\end{array}$ & $\begin{array}{c}-1.458^{* * *} \\
(0.458)\end{array}$ & & & $\begin{array}{c}-0.215^{* * *} \\
(0.036)\end{array}$ & & $\begin{array}{c}-0.008^{*} \\
(0.004)\end{array}$ & \\
\hline$\Delta \ln (1+$ state sales tax rate $)$ & & & $\begin{array}{c}-2.245^{* *} \\
(0.908)\end{array}$ & $\begin{array}{c}-1.744^{* * *} \\
(0.566)\end{array}$ & & $\begin{array}{c}-0.171^{* *} \\
(0.069)\end{array}$ & & $\begin{array}{l}-0.007 \\
(0.015)\end{array}$ \\
\hline Period FE & Yes & Yes & Yes & Yes & Yes & Yes & Yes & Yes \\
\hline Household FE & Yes & Yes & Yes & Yes & & & & \\
\hline Product FE & & & & & Yes & Yes & Yes & Yes \\
\hline ZIP3 FE & & & & & Yes & Yes & Yes & Yes \\
\hline Observations & $4,140,969$ & $4,142,698$ & $5,928,529$ & $5,928,499$ & $4,333,000$ & $5,862,621$ & $4,333,000$ & $5,862,621$ \\
\hline R-squared & 0.014 & 0.014 & 0.013 & 0.013 & 0.011 & 0.010 & 0.189 & 0.177 \\
\hline
\end{tabular}

Notes: Dependent variables in columns 1 to 4 are monthly changes in logged quantities (items) purchased by each household in the Nielsen Consumer Panel. Dependent variables in column 5 to 8 are monthly changes in sales-weighted average prices by product group and ZIP-3 code for all retailers in the Nielsen Retail Scanner Panel. For robustness, the dependent variables are winsorized at the 1\% level. Regressions span 2004-2014 for state sales tax rate changes using the Nielsen Consumer Panel (columns 3 and 4) respectively 2006-2014 using the Nielsen Retail Scanner Panel (columns 6 and 8), and 2008-2014 for total sales tax rate changes (columns 1, 2, 5, and 7). Robust standard errors in parentheses adjust for arbitrary within-product correlations and heteroskedasticity and are clustered at the ZIP-3 code for total sales tax rate changes and at the state level for state sales tax rate changes. 
Table 4: Tax-Exempt Spending Response to a Sales Tax Increase

\begin{tabular}{|c|c|c|c|c|c|c|c|c|}
\hline \multirow{4}{*}{$\begin{array}{l}\text { Data source: } \\
\text { Dependent variables: } \\
\text { log change of monthly exempt retail } \\
\text { spending (Panels A and B) and } \\
\text { exempt retail sales (Panle C). }\end{array}$} & \multicolumn{5}{|c|}{ Nielsen Consumer Panel (NCP) } & \multirow{2}{*}{\multicolumn{3}{|c|}{$\begin{array}{c}\text { Nielsen Retailer Panel (NRP) } \\
\text { C. Store Sales }\end{array}$}} \\
\hline & \multicolumn{2}{|c|}{ A. Main Analysis } & \multicolumn{3}{|c|}{ B. Robustness } & & & \\
\hline & Baseline & $\begin{array}{l}\text { State tax } \\
\text { rate only }\end{array}$ & $\begin{array}{c}\text { Household } \\
\text { charac. }\end{array}$ & $\begin{array}{l}\text { Business } \\
\text { cycle }\end{array}$ & $\begin{array}{c}\text { State-period } \\
\text { FE }\end{array}$ & Baseline & $\begin{array}{l}\text { Business } \\
\text { cycle }\end{array}$ & $\begin{array}{c}\text { State-period } \\
\text { FE }\end{array}$ \\
\hline & $(1)$ & $(2)$ & $(3)$ & $(4)$ & $(5)$ & $(6)$ & $(7)$ & $(8)$ \\
\hline$\Delta \ln (1+$ total sales tax rate $)$ & $\begin{array}{c}-1.395^{* * *} \\
(0.513)\end{array}$ & & $\begin{array}{c}-1.393^{* * *} \\
(0.513)\end{array}$ & $\begin{array}{c}-1.329 * * * \\
(0.513)\end{array}$ & $\begin{array}{c}-1.215^{* *} \\
(0.557)\end{array}$ & $\begin{array}{c}-4.243^{* * *} \\
(1.249)\end{array}$ & $\begin{array}{c}-4.162^{* * *} \\
(1.248)\end{array}$ & $\begin{array}{c}-4.120^{* * *} \\
(1.363)\end{array}$ \\
\hline$\Delta \ln (1+$ state sales tax rate $)$ & & $\begin{array}{c}-1.618^{* *} \\
(0.656)\end{array}$ & & & & & & \\
\hline Period FE & Yes & Yes & Yes & Yes & & Yes & Yes & \\
\hline Household FE & Yes & Yes & Yes & Yes & Yes & & & \\
\hline Household characteristics & & & Yes & Yes & Yes & & & \\
\hline Local unemployment rate & & & & Yes & Yes & & Yes & Yes \\
\hline State-period FE & & & & & Yes & & & Yes \\
\hline Store FE & & & & & & Yes & Yes & Yes \\
\hline Observations & $4,095,406$ & $5,865,177$ & $4,095,406$ & $4,095,406$ & $4,095,406$ & $2,303,059$ & $2,303,059$ & $2,303,059$ \\
\hline R-squared & 0.015 & 0.014 & 0.015 & 0.015 & 0.016 & 0.141 & 0.141 & 0.150 \\
\hline
\end{tabular}


Table 5: Evidence of Shopping Complementarity

\begin{tabular}{|c|c|c|c|c|c|c|c|c|}
\hline \multirow{4}{*}{ Dependent variable: } & \multicolumn{4}{|c|}{ A. Revealed Cost Approach } & \multicolumn{2}{|c|}{ B. Trip Complementarity } & \multirow{2}{*}{\multicolumn{2}{|c|}{$\begin{array}{l}\text { C. Placebo Test } \\
\text { online purchases }\end{array}$}} \\
\hline & \multicolumn{2}{|c|}{ frequent shoppers } & \multicolumn{2}{|c|}{ infrequent shoppers } & \multirow{3}{*}{$\begin{array}{l}\text { combined trips } \\
\Delta \ln (\text { exempt }) \\
\text { (5) }\end{array}$} & \multirow{3}{*}{$\begin{array}{c}\text { separate trips } \\
\Delta \ln (\text { exempt }) \\
(6)\end{array}$} & & \\
\hline & $\Delta \ln ($ exempt $)$ & $\Delta \ln ($ taxable $)$ & $\Delta \ln ($ exempt $)$ & $\Delta \ln ($ taxable $)$ & & & $\Delta \ln ($ exempt $)$ & $\Delta \ln ($ taxable $)$ \\
\hline & $(1)$ & $(2)$ & $(3)$ & $(4)$ & & & $(7)$ & $(8)$ \\
\hline$\Delta \ln (1+$ sales tax rate $)$ & $\begin{array}{l}-0.010 \\
(0.756)\end{array}$ & $\begin{array}{c}-2.202^{* *} \\
(0.910)\end{array}$ & $\begin{array}{c}-2.236^{*} \\
(1.191)\end{array}$ & $\begin{array}{l}-2.406^{*} \\
(1.451)\end{array}$ & $\begin{array}{c}-2.109 * * \\
(0.828)\end{array}$ & $\begin{array}{l}-0.813 \\
(1.16)\end{array}$ & $\begin{array}{c}0.145 \\
(0.464)\end{array}$ & $\begin{array}{c}1.592^{* *} \\
(0.709)\end{array}$ \\
\hline Period FE & Yes & Yes & Yes & Yes & Yes & Yes & Yes & Yes \\
\hline Household FE & Yes & Yes & Yes & Yes & Yes & Yes & Yes & Yes \\
\hline Observations & $1,086,921$ & $1,091,667$ & 934,657 & 951,890 & $1,049,599$ & 895,365 & $6,868,924$ & $6,868,924$ \\
\hline R-squared & 0.016 & 0.017 & 0.022 & 0.020 & 0.017 & 0.018 & 0.004 & 0.005 \\
\hline $\begin{array}{l}\text { otes: Sales tax rates ir } \\
\text { lumns } 7 \text { and } 8 \text { use sta } \\
\text { lelsen Consumer Panel } \\
\text { ips), while infrequent s } \\
\text { mple into households } \\
\text { irchases. For robustnes } \\
04-2014 \text { for state sal } \\
\text { teroskedasticity and ar }\end{array}$ & $\begin{array}{l}\text { in Columns } 1 \\
\text { ate sales tax ra } \\
\text { l data. Freque } \\
\text { shoppers in Co } \\
\text { who possess th } \\
\text { Ss, the depende } \\
\text { les tax rate c } \\
\text { re clustered at }\end{array}$ & $\begin{array}{l}\text { to } 6 \text { combine } \\
\text { ates. The dep } \\
\text { ent shoppers i } \\
\text { olumns } 3 \text { and } \\
\text { te most dispar } \\
\text { ent variables } \\
\text { changes. Rob } \\
\text { the ZIP code }\end{array}$ & (Column 6) & $\begin{array}{l}\text { within a ZI } \\
\text { is the monthl } \\
\text { nd } 2 \text { are cons } \\
\text { monthly tri } \\
\text { and most cor } \\
\text { it the } 1 \% \text { leve }\end{array}$ & $\begin{array}{l}\text { ow the 25th } p \\
\text { ed (Column 5) } \\
\text { gressions span }\end{array}$ & $\begin{array}{l}\text { tate, county, } \\
\text { mpt or taxabl } \\
\text { monthly trip } \\
\text { ercentile ( } 9 \text { tr } \\
\text { shopping trips } \\
2008-2014 \text { for }\end{array}$ & $\begin{array}{l}\text { and special } \\
\text { ail spending } \\
\text { ove the } 75 \mathrm{t} \\
\text { Columns } 5 \\
\text { erms of tax } \\
\text { l sales tax }\end{array}$ & $\begin{array}{l}\text { districts, whil } \\
\text { s measured by } \\
\text { percentile (19 } \\
\text { ind } 6 \text { split the } \\
\text { le and exemp } \\
\text { e changes and }\end{array}$ \\
\hline
\end{tabular}


Table 6: Persistent Tax Incentives

\begin{tabular}{|c|c|c|c|c|c|c|c|c|}
\hline \multirow{4}{*}{ Dependent variable: } & \multicolumn{6}{|c|}{ A. Fraction Spent in Alternative Tax Jurisdiction } & \multicolumn{2}{|c|}{ B. Online Spending } \\
\hline & \multicolumn{4}{|c|}{ short-run response (one-month change) } & \multicolumn{2}{|c|}{ long-run (12-month change) } & short-run & long-run \\
\hline & \multicolumn{2}{|c|}{$\Delta \ln ($ frac. alt. ZIP $)$} & \multicolumn{2}{|c|}{$\Delta \ln ($ frac. in alt. state $)$} & \multirow{2}{*}{$\begin{array}{c}\Delta \ln (\text { alt. ZIP }) \\
(5)\end{array}$} & \multirow{2}{*}{$\begin{array}{c}\Delta \ln (\text { alt. state }) \\
(6)\end{array}$} & \multicolumn{2}{|c|}{$\Delta \ln ($ online spending) } \\
\hline & $(1)$ & $(2)$ & $(3)$ & $(4)$ & & & $(7)$ & $(8)$ \\
\hline$\Delta \ln (1+$ total sales tax rate $)$ & $\begin{array}{l}-0.075 \\
(0.072)\end{array}$ & $\begin{array}{c}-0.182^{* * *} \\
(0.056)\end{array}$ & & & $\begin{array}{c}-0.674^{* * *} \\
(0.093)\end{array}$ & & & \\
\hline $\begin{array}{l}\Delta \ln (1+\text { total sales tax rate }) \\
\quad \times \text { avg. fraction in alt. ZIP3 }\end{array}$ & & $\begin{array}{c}1.497 \\
(0.951)\end{array}$ & & & $\begin{array}{c}5.484^{* * *} \\
(1.507)\end{array}$ & & & \\
\hline$\Delta \ln (1+$ state sales tax rate $)$ & & & $\begin{array}{l}-0.003 \\
(0.027)\end{array}$ & $\begin{array}{l}-0.017 \\
(0.019)\end{array}$ & & $\begin{array}{c}-0.199 * * * \\
(0.034)\end{array}$ & $\begin{array}{l}1.703^{* *} \\
(0.824)\end{array}$ & $\begin{array}{l}1.591^{* *} \\
(0.791)\end{array}$ \\
\hline $\begin{array}{l}\Delta \ln (1+\text { state sales tax rate }) \\
\quad \times \text { avg. fraction in alt. state }\end{array}$ & & & & $\begin{array}{c}1.334 \\
(2.639)\end{array}$ & & $\begin{array}{c}4.731 \\
(3.907)\end{array}$ & & \\
\hline Period FE & Yes & Yes & Yes & Yes & Yes & Yes & Yes & Yes \\
\hline Household FE & Yes & Yes & Yes & Yes & Yes & Yes & Yes & Yes \\
\hline Observations & $4,231,065$ & $4,231,065$ & $6,049,454$ & $6,049,454$ & $2,510,373$ & $4,010,860$ & $6,868,924$ & $3,010,794$ \\
\hline R-squared & 0.005 & 0.005 & 0.005 & 0.005 & 0.119 & 0.101 & 0.005 & 0.044 \\
\hline Average of interaction variable & & 0.079 & & 0.017 & 0.079 & 0.016 & & \\
\hline
\end{tabular}

Notes: Regressions span 2004-2014 for state sales tax rate changes and 2008-2014 for total sales tax rate changes. Panel A examines changes in the monthly fraction of a household's retail spending in an alternative tax jurisdiction outside the household's residential 3-digit ZIP code, either an alternative 3-digit ZIP code or an alternative state. The dependent variable in Columns 1 to 4 are monthly changes while Columns 5 and 6 use 12-moth changes (e.g., change from March 2013 to March 2014). Panel B examines changes in the log of total online spending, including mail orders. Robust standard errors in parentheses adjust for arbitrary withinhousehold correlations and heteroskedasticity and are clustered at the ZIP code for total sales tax rate changes and at the state level for state sales tax rate changes. 



\section{Online Appendix of \\ "Shopping for Lower Sales Tax Rates"}

Scott R. Baker Stephanie Johnson Lorenz Kueng

\section{A. Additional Data}

\section{A.1 Nielsen Retail Scanner (Retail Prices)}

With the Nielsen Retail Scanner Panel (NRP), price and quantity information is available at the store level for each UPC carried by a covered retailer and span the years 2006-2014. An average (quantity weighted) price is reported, by UPC, for each store every week. ${ }^{36} \mathrm{NRP}$ covers 125 product groups with more than 3.2 million individual UPCs. Units are consistently standardized and most products are measured in ounces (OZ, 51\%), count (CT, 45\%) or ml (ML, $2 \%)$.

\section{A.2 PromoData (Wholesale Prices)}

We use PromoData to measure wholesale prices for grocery and retail goods. Promo obtains its information from one (confidential) major wholesaler in each market. ${ }^{37}$ One downside to this approach is that, since no single wholesaler carries every SKU in a given market, information about the universe of goods is not observed. Overall, Promo prices are available for 32 markets after removing redundant markets and combining overlapping markets. ${ }^{38}$

Data on wholesale prices are available from 2006 - 2012. However, during 2012 the data loses a significant amount of coverage. For this reason, we perform robustness tests excluding 2012 data from our sample. PromoData contains all changes in price or deals that are run by the wholesaler. Thus, we take prices as constant between observations, based on the last observed price data. We then are able to collapse prices to a monthly level for each product group. To arrive at consistent unit prices within type of product (eg. product groups), we scale the observed wholesale prices by the number of goods in a 'pack' and by the size of the unit (eg. number of ounces in a candy bar and number of candy bars in a box). To make meaningful unit price comparisons we need to know the units associated with each good. Unfortunately unit information is often not provided

\footnotetext{
${ }^{36}$ For a given store, coverage over time is stable and relatively complete across all years. Unit prices are calculated as price/(prmult $\times$ size1_amt $)$.

${ }^{37}$ By only using one wholesaler, Promo relies on the Robinson-Patman Anti-Price Discrimination Act of 1936 that prohibits price discrimination. In particular, it prevents wholesalers from offering special discounts to large chain stores but not to other, smaller retailers.

${ }^{38}$ Leveraging this regional information provides additional variation but introduces more measurement error given less complete coverage in any given market both with respect to corresponding Nielsen product groups in the cross-section and time-series coverage of specific products.
} 
or is inconsistently coded (e.g., CT, PACK, EACH, OZ, O etc.). We use the modal unit within UPC to impute missing values. The intuition is that if a product is recorded as being measured in $\mathrm{OZ}$ most of the time units are reported, it is probably measured in OZ.

\section{A.3 Matching Wholesaler and Retailer Data}

Given the large number of products in the retailer dataset we aggregate retail unit prices to the product group level before matching with wholesale prices. We assign products in the wholesaler data to Nielsen product groups by matching at the UPC level. The mapping is not one-to-one due to differences in end-digits when shifting to UPCs of different levels of granularity (e.g., some are reported with retailer specific end-digits, etc.). This leads to multiple Nielsen UPCs corresponding to a single Promo UPC for some goods. However, this appears to have little effect when merging Nielsen product groups to their Promo equivalents.

As a consistency check we also match retail and wholesale prices by UPC at a single point in time. The implied markup distribution supports the accuracy of both the raw data and our unit price calculations, with $90 \%$ of markups falling between $-7 \%$ and $135 \%$. We calculate Promo coverage of Nielsen product groups as the percentage of UPCs in each Nielsen product group that can be found in Promo. Overall, we see that about $4 \%$ of overall UPCs in Nielsen are also covered directly in the wholesale data for a given market. Aggregating across markets to the national level, this coverage increases somewhat.

The two datasets are merged based on the weekly date. That is, Promo prices are those associated with the week containing the Nielsen week-ending Saturday. For a Nielsen retailer using a 7-day period ending on Saturday the periods correspond closely. However, as mentioned above this is not the case for all retailers. For a retailer using a Thursday to Wednesday week, the Nielsen prices would pre-date the Promo prices by a few days.

Comparing unit prices is not completely straightforward as Promo units are missing for many products. As discussed above, we impute some missing units based on the modal unit reported in Promo for that UPC. When merging, we retain only UPCs for which the imputed Promo unit matches the Nielsen unit. A coarse attempt is made to standardize the more common Promo units before matching. In particular we assume $O$ and $Z$ refers to $O Z$ and $C, C N T, P K, E A, E A C H, S T K, R O L, R L, P C, \#, C T N$ refer to $C T$.

\section{A.4 State Ballot Propositions}

To study tax salience, we focus on sales tax changes triggered by state-level ballot propositions. Using Ballotpedia.com we identify all state ballot propositions that involve changes in state sales taxes from 2004-2015. These data include propositions in Arizona, Arkansas, California, Colorado, Georgia, Maine, Massachusetts, Michigan, Minnesota, Missouri, South Dakota, and Washington, with some states having multiple ballots regarding sales taxes.

In total, we observe 20 propositions with potential effects ranging from a decline in sales taxes of $3.25 \mathrm{ppt}$ to an increase in sales taxes of 1 ppt. 10 of the 20 propositions were successful, 9 were 
unsuccessful, and one was partially successful (took effect in a subset of state counties). 9 of the 20 propositions took place in November with the remaining propositions spread across February, May, June, and August.

\section{B. Derivation of the Shopping Model}

\section{B.1 Supporting Calculations}

\section{B.1.1 Within-Period Value Function, $U\left(C_{t_{n}}, \Delta t_{n}\right)$}

Define $f(\Delta t ; \alpha)=\frac{e^{\alpha \Delta t}-1}{\alpha}$ with $f^{\prime}=e^{\alpha \Delta t}, f^{(n)}=\alpha^{n-1} e^{\alpha \Delta t}, f(0)=0, \lim _{\alpha \rightarrow 0} f(\Delta t ; \alpha)=\Delta t$ and a second-order approximation around $\Delta t=0$ is $f(\Delta t ; \alpha) \approx\left(1+\frac{\alpha}{2} \Delta t\right) \Delta t$. The Lagrangian of $(3)$ is $\int_{x=0}^{\Delta t_{n}}\left[e^{-\rho t} u\left(C\left(t_{n}+x\right)\right)-\lambda e^{\delta x} C\left(t_{n}+x\right)\right] d x+\lambda S_{t_{n}}$. Defining $F\left(C, C^{\prime}, t\right)=e^{-\rho t} u\left(C\left(t_{n}+t\right)\right)-$ $\lambda e^{\delta t} C\left(t_{n}+t\right)$, the general form of the Euler condition of this problem is $F_{C}=\frac{d F_{C^{\prime}}}{d t}=F_{C^{\prime} C} C^{\prime}+$ $F_{C^{\prime} C^{\prime}}+F_{C^{\prime} t} C^{\prime \prime}$. Since $F_{C^{\prime}}=0$, this reduces to $F_{C}=0$, which implies $e^{\delta x} \lambda=e^{-\rho x} u^{\prime}\left(C\left(t_{n}+x\right)\right)=$ $e^{-\rho x} C\left(t_{n}+x\right)^{-1 / \sigma}$. Hence $C\left(t_{n}+x\right)=\lambda^{-\sigma} e^{\gamma x}$ and $C_{t_{n}}=C\left(t_{n}\right)=\lambda^{-\sigma}$, where $\gamma=-(\delta+\rho) \sigma$,

$$
C\left(t_{n}+x\right)=C_{t_{n}} e^{\gamma x}
$$

Plugging into the constraint yields $S_{t_{n}}=\int_{0}^{\Delta t_{n}} e^{\delta x} C\left(t_{n}+x\right) d x=\lambda^{-\sigma} \int_{x=0}^{\Delta t_{n}} e^{(\delta+\gamma) x} d x=\lambda^{-\sigma} f\left(\Delta t_{n} ; \phi\right)$, with $\phi=\delta+\gamma=\delta-\sigma(\delta+\rho)$, so that

$$
S_{t_{n}}=C_{t_{n}} \cdot f\left(\Delta t_{n} ; \phi\right)
$$

Plugging into the objective function and integrating yields ${ }^{39}$

$$
\begin{aligned}
U\left(C_{t_{n}}, \Delta t_{n}\right) & =\int_{x=0}^{\Delta t_{n}} e^{-\rho x} u\left(C\left(t_{n}+x\right)\right) d x=u\left(C_{t_{n}}\right) \int_{x=0}^{\Delta t_{n}} e^{-\rho x} e^{\frac{\sigma-1}{\sigma} \gamma x} d x \\
& =u\left(C_{t_{n}}\right) \int_{x=0}^{\Delta t_{n}} e^{\phi x} d x \\
& =u\left(C_{t_{n}}\right) \cdot f\left(\Delta t_{n} ; \phi\right) .
\end{aligned}
$$

\section{B.1.2 Inventories, $S_{t_{n}}, s_{i, t_{n}}$}

Between shopping transactions, inventory evolves according to the first-order ordinary differential equation $\dot{s}_{i}(x)=-\delta s_{i}(x)-c_{i}(x)$, with boundary conditions $s_{i}\left(t_{n}\right)=s_{i, t_{n}}$ and $s_{i}\left(t_{n+1}^{-}\right)=0$. The solution for $x \in\left[t_{n}, t_{n+1}\right)$ is

$$
s_{i}\left(t_{n}+x\right)=e^{-\delta x}\left[s_{i, t_{n}}-\int_{z=0}^{x} e^{\delta z} c_{i}\left(t_{n}+z\right) d z\right]
$$

39 Also note that $U\left(C_{t_{n}}, \Delta t_{n}\right)=U\left(S_{t_{n}}, \Delta t_{n}\right)=u\left(S_{t_{n}}\right) \cdot f\left(\Delta t_{n} ; \phi\right)^{1 / \sigma}$. 
Hicksian demand $c_{i}(t)$ is a function of the relative price at the transaction date $t_{n}, p_{i, t_{n}} / P_{t_{n}}$ such that $c_{i}\left(t_{n}+z\right)=b_{i}\left(\frac{p_{i, t_{n}}}{P_{t_{n}}}\right)^{-\eta} C\left(t_{n}+z\right)=b_{i}\left(\frac{p_{i, t_{n}}}{P_{t_{n}}}\right)^{-\eta} C_{t_{n}} e^{\gamma z}$. We can use individual inventories $s_{i}\left(t_{n}\right)$ to define inventories of the composite consumption good

$$
\begin{aligned}
S\left(t_{n}+x\right) & \equiv \frac{\sum_{i} p_{i, t_{n}} s_{i}\left(t_{n}+x\right)}{P_{t_{n}}}=e^{-\delta x}[S_{t_{n}}-\int_{z=0}^{x} e^{\delta z} \underbrace{\frac{\sum_{i} b_{i}\left(\frac{p_{i, t_{n}}}{P_{t_{n}}}\right)^{-\eta} p_{i, t_{n}}}{P_{t_{n}}}}_{=1} C\left(t_{n}+z\right) d z] \\
& =e^{-\delta x}\left[S_{t_{n}}-C_{t_{n}} \int_{z=0}^{x} e^{(\delta+\gamma) z} d z\right] \\
& =e^{-\delta x}\left[S_{t_{n}}-C_{t_{n}} f(x ; \phi)\right] .
\end{aligned}
$$

The condition $s_{i}\left(t_{n}+\Delta t_{n}\right)=s_{i}\left(t_{n+1}^{-}\right)=0$ implies $S\left(t_{n}+\Delta t_{n}\right)=S\left(t_{n+1}^{-}\right)=0$ and

$$
S_{t_{n}}=C_{t_{n}} f\left(\Delta t_{n} ; \phi\right)
$$

Similarly, using $s_{i}\left(t_{n+1}^{-}\right)=0=e^{-\delta \Delta t_{n}}\left[s_{i, t_{n}}-\int_{z=0}^{\Delta t_{n}} e^{\delta z} c_{i}\left(t_{n}+z\right) d z\right]$, beginning-of-period inventories for the individual goods are

$$
\begin{aligned}
s_{i, t_{n}} & =\int_{z=0}^{\Delta t_{n}} e^{\delta z} c_{i}\left(t_{n}+z\right) d z \\
& =b_{i}\left(\frac{p_{i, t_{n}}}{P_{t_{n}}}\right)^{-\eta} C_{t_{n}} \int_{z=0}^{\Delta t_{n}} e^{(\delta+\gamma) z} d z=b_{i}\left(\frac{p_{i, t_{n}}}{P_{t_{n}}}\right)^{-\eta} C_{t_{n}} f\left(\Delta t_{n} ; \phi\right) \\
& =b_{i}\left(\frac{p_{i, t_{n}}}{P_{t_{n}}}\right)^{-\eta} S_{t_{n}}
\end{aligned}
$$

and the expenditure share of good $i$ is

$$
B_{i, t_{n}}=\frac{p_{i, t_{n}} s_{i, t_{n}}}{P_{t_{n}} S_{t_{n}}}=b_{i}\left(\frac{p_{i, t_{n}}}{P_{t_{n}}}\right)^{1-\eta} .
$$

\section{B.1.3 Tax Elasticity of the Price Index}

The effective cost-of-living price index is $P(\tau)=\left[b_{\tau}(1+\tau)^{1-\eta} \tilde{p}_{\tau}^{1-\eta}+b_{e} \tilde{p}_{e}^{1-\eta}\right]^{1 /(1-\eta)}$, where $\tilde{p}_{i}$ is the pre-tax price so that $p_{\tau}=(1+\tau) \tilde{p}_{\tau}$ and $p_{e}=\tilde{p}_{e}$. Hence

$$
\begin{aligned}
\frac{d \ln P(\tau)}{d \ln (1+\tau)} & =\frac{1+\tau}{P} \frac{d P}{d(1+\tau)} \\
& =\frac{1+\tau}{P} \frac{1}{1-\eta} P^{\eta}(1-\eta)(1+\tau)^{-\eta} b_{\tau} \tilde{p}_{\tau}^{1-\eta} \\
& =b_{\tau}\left(\frac{(1+\tau) \tilde{p}_{\tau}}{P}\right)^{1-\eta}=b_{\tau}\left(\frac{p_{\tau}}{P}\right)^{1-\eta}
\end{aligned}
$$


The taxable expenditure share is

$$
B_{\tau}=\frac{p_{\tau} s_{\tau}}{P S}=\frac{p_{\tau}}{P S} b_{\tau}\left(\frac{p_{\tau}}{P}\right)^{-\eta} S=b_{\tau}\left(\frac{p_{\tau}}{P}\right)^{1-\eta}
$$

Hence,

$$
\frac{d \ln P(\tau)}{d \ln (1+\tau)}=B_{\tau}
$$

\section{B.2 Model Solution}

\section{B.2.1 Transaction Interval, $\Delta t_{n}$}

Define $C=C_{\Delta t}$ with consumption flow $C_{\Delta t}=\int_{x=0}^{\Delta t} C\left(t_{n}+x\right) d x=C_{t_{n}} f(\gamma)$ so that $S=C \frac{f(\phi)}{f(\gamma)}$ and

$$
\begin{aligned}
& U=u(C) \cdot f(\gamma)^{\frac{1}{\sigma}-1} \cdot f(\phi)=u(C / f(\gamma)) \cdot f(\phi)=u(S) \cdot f(\phi)^{\frac{1}{\sigma}} \\
& K=\kappa+P C \cdot \frac{f(\phi)}{f(\gamma)}=\kappa+P S .
\end{aligned}
$$

The partial derivatives of $U$ and $K$ with respect to $C$ are

$$
\begin{aligned}
& \partial_{C} K^{\prime}=P \frac{f(\phi)}{f(\gamma)}=\frac{P S}{C} \\
& \partial_{C} U^{\prime}=u^{\prime}(C) \cdot f(\gamma)^{\frac{1}{\sigma}-1} f(\phi)=U \cdot \frac{u^{\prime}(C)}{u(C)}
\end{aligned}
$$

such that (6) becomes

$$
V^{\prime}=\frac{\partial_{C} U^{\prime}}{\partial_{C} K^{\prime}}=\frac{\left(1-\frac{1}{\sigma}\right) U}{P S}
$$

The partial derivatives of $U$ and $K$ with respect to $\Delta t$ are

$$
\partial_{\Delta t} K^{\prime}=P C\left[-f(\gamma)^{-2} f(\phi) e^{\gamma \Delta t}+f(\gamma)^{-1} e^{\phi \Delta t}\right]=P S\left[\frac{e^{\phi \Delta t}}{f(\phi)}-\frac{e^{\gamma \Delta t}}{f(\gamma)}\right]
$$

and

$$
\begin{aligned}
\partial_{\Delta t} U^{\prime} & =u(C)\left[\left(\frac{1}{\sigma}-1\right) f(\gamma)^{\frac{1}{\sigma}-2} f(\phi) e^{\gamma \Delta t}+f(\gamma)^{\frac{1}{\sigma}-1} e^{\phi \Delta t}\right] \\
& =u(C) f(\gamma)^{\frac{1}{\sigma}-1} f(\phi)\left[\frac{e^{\phi \Delta t}}{f(\phi)}-\left(1-\frac{1}{\sigma}\right) \frac{e^{\gamma \Delta t}}{f(\gamma)}\right] \\
& =U\left[\frac{e^{\phi \Delta t}}{f(\phi)}-\frac{e^{\gamma \Delta t}}{f(\gamma)}+\frac{1}{\sigma} \frac{e^{\gamma \Delta t}}{f(\gamma)}\right]=U\left[\frac{\partial_{\Delta t} K}{P S}+\frac{1}{\sigma} \frac{e^{\gamma \Delta t}}{f(\gamma)}\right]
\end{aligned}
$$


Necessary condition for $\Delta t_{n}$ Necessary condition (8) can also be written as

$$
\partial_{\Delta t} U_{t_{n}}^{\prime}-e^{-\rho \Delta t_{n}} \rho V_{t_{n+1}}=\left[\partial_{\Delta t} K_{t_{n}}^{\prime}-e^{-r \Delta t_{n}} r w_{t_{n+1}}\right] e^{(r-\rho) \Delta t_{n}} V_{t_{n+1}}^{\prime} .
$$

The right-hand side is

$$
\begin{aligned}
e^{(r-\rho) \Delta t_{n}} V^{\prime}\left(w_{t_{n+1}}\right)\left[\partial_{\Delta t} K_{t_{n}}^{\prime}-r\left(w_{t_{n}}-K_{t_{n}}\right)\right] & =e^{(r-\rho) \Delta t_{n}} V^{\prime}\left(w_{t_{n+1}}\right)\left[\partial_{\Delta t} K_{t_{n}}^{\prime}-e^{-r \Delta t_{n}} r w_{t_{n+1}}\right] \\
& =\left(1-\frac{1}{\sigma}\right) U_{t_{n}}\left[\frac{\partial_{\Delta t_{n}} K_{t_{n}}^{\prime}}{P_{t_{n}} S_{t_{n}}}-\frac{e^{-r \Delta t_{n}} r w_{t_{n+1}}}{P_{t_{n}} S_{t_{n}}}\right] \\
& =\left(1-\frac{1}{\sigma}\right) U_{t_{n}}\left[\frac{e^{\phi \Delta t_{n}}}{f(\phi)}-\frac{e^{\gamma \Delta t_{n}}}{f(\gamma)}-\frac{e^{-r \Delta t_{n}} r w_{t_{n+1}}}{P_{t_{n}} S_{t_{n}}}\right]
\end{aligned}
$$

and the left-hand side is

$$
\begin{aligned}
\partial_{\Delta t} U_{t_{n}}^{\prime}-e^{-\rho \Delta t_{n}} \rho V\left(w_{t_{n+1}}\right) & =U_{t_{n}}\left[\frac{\partial_{\Delta t} K_{t_{n}}^{\prime}}{P_{t_{n}} S_{t_{n}}}+\frac{1}{\sigma} \frac{e^{\gamma \Delta t_{n}}}{f(\gamma)}\right]-e^{-\rho \Delta t_{n}} \rho V\left(w_{t_{n+1}}\right) \\
& =U_{t_{n}}\left[\frac{e^{\phi \Delta t_{n}}}{f(\phi)}-\left(1-\frac{1}{\sigma}\right) \frac{e^{\gamma \Delta t_{n}}}{f(\gamma)}\right]-e^{-\rho \Delta t_{n}} \rho V\left(w_{t_{n+1}}\right) .
\end{aligned}
$$

Hence, necessary condition (8), which implicitly defines $\Delta t_{n}$, can be rewritten as

$$
\frac{\rho e^{-\rho \Delta t_{n}} V\left(w_{t_{n+1}}\right)}{U\left(S_{t_{n}}, \Delta t_{n}\right)}-\left(1-\frac{1}{\sigma}\right) \frac{r e^{-r \Delta t_{n}} w_{t_{n+1}}}{P_{t_{n}} S_{t_{n}}}=\frac{1}{\sigma} \frac{e^{\phi \Delta t_{n}}}{f\left(\Delta t_{n} ; \phi\right)}
$$

or substituting out inventories,

$$
\frac{\rho e^{-\rho \Delta t_{n}} V\left(w_{t_{n+1}}\right)}{u\left(C_{t_{n}}\right)}-\left(1-\frac{1}{\sigma}\right) \frac{r e^{-r \Delta t_{n}} w_{t_{n+1}}}{P_{t_{n}} C_{t_{n}}}=\frac{1}{\sigma} e^{\phi \Delta t_{n}} .
$$

\section{B.2.2 Final Stationary State (starting at $t_{s s}$ )}

In the stationary state with $r=\rho,(4)$ implies

$$
\begin{aligned}
V_{t_{s s}} & =\left(1-e^{-\rho \Delta t_{s s}}\right)^{-1} U_{t_{s s}} \\
w_{t_{s s}} & =\left(1-e^{-r \Delta t_{s s}}\right)^{-1} K_{t_{s s}}=\left(1-e^{-r \Delta t_{s s}}\right)^{-1}\left(\kappa+P_{t_{s s}} S_{t_{s s}}\right)
\end{aligned}
$$

Plugging the stationary-state value function and wealth into (15) and evaluating at the stationary state $\rho=r$, noting that $e^{-r \Delta t} r\left(1-e^{-r \Delta t}\right)^{-1}=f(\Delta t ; r)^{-1}$, yields (9),

$$
(1-\sigma) \frac{\kappa}{P_{t_{s s}} S_{t s s}}=e^{\phi \Delta t_{s s}} \frac{f\left(\Delta t_{s s} ; r\right)}{f\left(\Delta t_{s s} ; \phi\right)}-1
$$

or in terms of consumption,

$$
(1-\sigma) \frac{\kappa}{P_{t_{s s}} C_{t_{s s}}}=e^{\phi \Delta t_{s s}} f\left(\Delta t_{s s} ; r\right)-f\left(\Delta t_{s s} ; \phi\right) .
$$


Furthermore, by plugging (17) into (9), we can express the optimal shopping cycle in the stationary state instead as a function of the total level of wealth in stationary state, $w_{t_{s s}}{ }^{40}$

$$
(1-\sigma)\left[\frac{\kappa}{\left(1-e^{-r \Delta t_{s s}}\right) w_{t_{s s}}-\kappa}\right]=e^{\phi \Delta t_{s s}} \frac{f\left(\Delta t_{s s} ; r\right)}{f\left(\Delta t_{s s} ; \phi\right)}-1
$$

Approximate steady-state trip interval ("square-root formula") Define the right-hand side of (18)

$$
F(\Delta t)=e^{\phi \Delta t} f(\Delta t ; r)-f(\Delta t ; \phi)
$$

Taking a second-order Taylor expansion of $F$ around $\Delta t=0$

$$
F(\Delta t) \approx F(0)+F^{\prime}(0) \Delta t+F^{\prime \prime}(0) \frac{(\Delta t)^{2}}{2}
$$

noting that

$$
\begin{aligned}
F(0) & =0 & & \\
F^{\prime}(\Delta t) & =\phi e^{\phi \Delta t} f(\Delta t ; \phi)+e^{(\phi+\delta) \Delta t}-e^{\phi \Delta t} & & \Rightarrow F^{\prime}(0)=0 \\
F^{\prime \prime}(\Delta t) & =\phi^{2} e^{\phi \Delta t} f(\Delta t ; \phi)+(2 \phi+r) e^{(\phi+r) \Delta t}-\phi e^{\phi \Delta t} & & \Rightarrow F^{\prime \prime}(0)=(1-\sigma)(\delta+r)
\end{aligned}
$$

yields

$$
F(\Delta t) \approx(1-\sigma)(\delta+r) \frac{(\Delta t)^{2}}{2}
$$

If $\sigma=0$ (which we cannot reject based on our estimates of the long-run spending response), then consumption is constant, in particular $C_{t_{n}}=C$, and does not depend on $\Delta t$. Hence the left-hand side of (18) is not affected by the Taylor expansion around $\Delta t=0$. Therefore, substituting the approximation of the right-hand side into (18) yields the approximate square root formula in the text,

$$
\Delta t_{s s} \approx \sqrt{\frac{\kappa}{\frac{\delta+r}{2} P_{t_{s s}} C_{t_{s s}}}}
$$

\section{B.2.3 Interim Shopping Period (starting at $t_{s s-1}$ )}

\section{A. Change of the iterim-period interval $\left(\Delta t_{s s-1}\right)$ Using (15) we have}

$$
\frac{1}{\sigma} \frac{e^{\phi \Delta t_{s s-1}}}{f\left(\Delta t_{s s-1} ; \phi\right)}=\frac{\rho e^{-\rho \Delta t_{s s-1}} V\left(w_{t_{s s}}\right)}{U\left(C_{t_{n}}, \Delta t_{n}\right)}-\left(1-\frac{1}{\sigma}\right) \frac{r e^{-r \Delta t_{s s-1}} w_{t_{s s}}}{P_{t_{s s-1}} S_{t_{s-1}}}
$$

\footnotetext{
40 Note that if $\sigma=1$ (i.e., income effect equals substitution effect) then $\Delta t_{s s}$ is not defined by (9) since the $\mathrm{LHS}=\mathrm{RHS}=0$ independent of $\Delta t_{s s}$, but instead is pinned down by the steady-state budget constraint.
} 


$$
\begin{aligned}
& =\frac{\rho e^{-\rho \Delta t_{s s-1}}\left(1-e^{-\rho \Delta t_{s s}}\right)^{-1} U_{t_{s s}}}{U_{t_{s s-1}}}-\left(1-\frac{1}{\sigma}\right) \frac{r e^{-r \Delta t_{s s-1}}\left(1-e^{-r \Delta t_{s s}}\right)^{-1}\left(\kappa+P_{t_{s s}} S_{t_{s s}}\right)}{P_{t_{s s-1}} S_{t_{s s-1}}} \\
& =r e^{-r \Delta t_{s s-1}}\left(1-e^{-r \Delta t_{s s}}\right)^{-1}\left[\frac{U_{t_{s s}}}{U_{t_{s s-1}}}-\left(1-\frac{1}{\sigma}\right)\left(\frac{P_{t_{s s}} S_{t_{s s}}}{P_{t_{s s-1}} S_{t_{s s-1}}}+\frac{\kappa}{P_{t_{s s-1}} S_{t_{s s-1}}}\right)\right] .
\end{aligned}
$$

Using (7) we find an expression for $U_{t_{s s}} / U_{t_{s s-1}}$,

$$
\begin{aligned}
\frac{U_{t_{s s}}}{U_{t_{s s-1}}} & =\frac{u\left(S_{t_{s s}}\right) f\left(\Delta t_{s s} ; \phi\right)^{1 / \sigma}}{u\left(S_{t_{s s-1}}\right) f\left(\Delta t_{s s-1} ; \phi\right)^{1 / \sigma}}=\left(\frac{S_{t_{s s}}}{S_{t_{s s-1}}}\right)^{1-1 / \sigma}\left(\frac{f\left(\Delta t_{s s} ; \phi\right)}{f\left(\Delta t_{s s-1} ; \phi\right)}\right)^{1 / \sigma} \\
& =e^{(\sigma-1)(r-\rho) \Delta t_{s s-1}}\left(\frac{P_{t_{s s}}}{P_{t_{s s-1}}}\right)^{1-\sigma} \frac{f\left(\Delta t_{s s} ; \phi\right)}{f\left(\Delta t_{s s-1} ; \phi\right)}
\end{aligned}
$$

and

$$
\begin{aligned}
\frac{P_{t_{s s}} S_{t_{s s}}}{P_{t_{s s-1}} S_{t_{s s-1}}}+\frac{\kappa}{P_{t_{s s-1}} S_{t_{s s-1}}} & =\frac{P_{t_{s s}} S_{t_{s s}}}{P_{t_{s s-1}} S_{t_{s s-1}}}\left(1+\frac{\kappa}{P_{t_{s s}} S_{t_{s s}}}\right) \\
& =e^{\sigma(r-\rho) \Delta t_{s s-1}}\left(\frac{P_{t_{s s}}}{P_{t_{s s-1}}}\right)^{1-\sigma} \frac{f\left(\Delta t_{s s} ; \phi\right)}{f\left(\Delta t_{s s-1} ; \phi\right)}\left(1+\frac{\kappa}{P_{t_{s s}} S_{t_{s s}}}\right) .
\end{aligned}
$$

Plugging back in and evaluating at $\rho=r$,

$$
\begin{aligned}
\frac{1}{\sigma} \frac{e^{\phi \Delta t_{s s-1}}}{f\left(\Delta t_{s s-1} ; \phi\right)} & =e^{-r\left(\Delta t_{s s-1}-\Delta t_{s s}\right)} f\left(\Delta t_{s s} ; r\right)^{-1}\left(\frac{P_{t_{s s}}}{P_{t_{s-1}}}\right)^{1-\sigma} \frac{f\left(\Delta t_{s s} ; \phi\right)}{f\left(\Delta t_{s s-1} ; \phi\right)}\left[1-\left(1-\frac{1}{\sigma}\right)\left(1+\frac{\kappa}{P_{t_{s s}} S_{t_{s s}}}\right)\right] \\
& =e^{-r\left(\Delta t_{s s-1}-\Delta t_{s s}\right)} f\left(\Delta t_{s s} ; r\right)^{-1}\left(\frac{P_{t_{s s}}}{P_{t_{s s-1}}}\right)^{1-\sigma} \frac{f\left(\Delta t_{s s} ; \phi\right)}{f\left(\Delta t_{s s-1} ; \phi\right)} \frac{1}{\sigma}\left[1+(1-\sigma) \frac{\kappa}{P_{t_{s s}} S_{t_{s s}}}\right] .
\end{aligned}
$$

Therefore,

$$
(1-\sigma) \frac{\kappa}{P_{t_{s s}} S_{t_{s s}}}=e^{\phi \Delta t_{s s-1}+r\left(\Delta t_{s s-1}-\Delta t_{s s}\right)} \frac{f\left(\Delta t_{s s} ; r\right)}{f\left(\Delta t_{s s} ; \phi\right)}\left(\frac{P_{t_{s s}}}{P_{t_{s s-1}}}\right)^{-(1-\sigma)}-1
$$

Substituting the left-hand side with (9)

$$
\left(\frac{P_{t_{s s}}}{P_{t_{s s-1}}}\right)^{(1-\sigma)}=e^{(\phi+r)\left(\Delta t_{s s-1}-\Delta t_{s s}\right)}=e^{(1-\sigma)(\delta+r)\left(\Delta t_{s s-1}-\Delta t_{s s}\right)}
$$

and taking logs yields

$$
\Delta t_{s s-1}-\Delta t_{s s}=\frac{\ln \left(P_{t_{s s}} / P_{t_{s s-1}}\right)}{\delta+r}
$$

Elasticity Hence, we obtain (11) by the following approximation,

$$
\frac{\ln \left(P_{t_{s s}} / P_{t_{s s-1}}\right)}{(\delta+r) \Delta t_{s s}}=\frac{\Delta t_{s s-1}-\Delta t_{s s}}{\Delta t_{s s}} \approx-\ln \left(\Delta t_{s s} / \Delta t_{s s-1}\right)
$$


such that

$$
\begin{aligned}
\varepsilon_{\Delta t_{s s-1}} & =\left.\frac{d \ln \left(\Delta t_{s s} / \Delta t_{s s-1}\right)}{d \ln \left(1+\tau_{t_{s s}}\right)}\right|_{\Delta t_{s s} \text { cons }}=-\frac{1}{(\delta+r) \Delta t_{s s}} \frac{d \ln \left(P_{t_{s s}} / P_{t_{s s-1}}\right)}{d \ln \left(1+\tau_{t_{s s}}\right)} \\
& =-\frac{B_{\tau}}{(\delta+r) \Delta t_{s s}} .
\end{aligned}
$$

B. Change of iterim-period spending $\left(s_{i, t_{s s-1}}\right)$ Beginning-of-period inventory of good $i$ is

$$
s_{i, t_{n}}=b_{i}\left(\frac{p_{i, t_{n}}}{P_{t_{n}}}\right)^{-\eta} S_{t_{n}}
$$

such that

$$
\frac{s_{i, t_{s s-1}}}{s_{i, t_{s s}}}=\left(\frac{p_{i, t_{s s}}}{p_{i, t_{s s-1}}}\right)^{\eta}\left(\frac{P_{t_{s s}}}{P_{t_{s s-1}}}\right)^{-\eta} \frac{S_{t_{s s-1}}}{S_{t_{s s}}} .
$$

Substituting Euler equation (7) evaluated at $\rho=r$ yields

$$
\frac{s_{i, t_{s s-1}}}{s_{i, t_{s s}}}=\left(\frac{p_{i, t_{s s}}}{p_{i, t_{s s-1}}}\right)^{\eta}\left(\frac{P_{t_{s s}}}{P_{t_{s s-1}}}\right)^{\sigma-\eta} \frac{f\left(\Delta t_{s s-1} ; \phi\right)}{f\left(\Delta t_{s s} ; \phi\right)} .
$$

Using the fact that $\frac{d \ln \left(P_{t s s} / P_{t_{s s-1}}\right)}{d \ln \left(1+\tau_{t s s}\right)}=B_{\tau}$, the compensated short-run spending elasticity of a forward-looking consumer is

$$
\begin{aligned}
\varepsilon_{s_{i, t_{s s-1}}} & \equiv \frac{d \ln \left(s_{i, t_{s s}} / s_{i, t_{s s-1}}\right)}{d \ln \left(1+\tau_{t_{s s}}\right)} \\
& =-(\sigma-\eta) \frac{d \ln \left(P_{t_{s s}} / P_{t_{s s-1}}\right)}{d \ln \left(1+\tau_{t_{s s}}\right)}-\eta \cdot \frac{d \ln \left(p_{i, t_{s s}} / p_{i, t_{s s-1}}\right)}{d \ln \left(1+\tau_{t_{s s}}\right)}-\frac{d \ln \left(f\left(\Delta t_{s s-1} ; \phi\right) / f\left(\Delta t_{s s} ; \phi\right)\right)}{d \ln \left(1+\tau_{t_{s s}}\right)} \\
& =-(\sigma-\eta) B_{\tau}-\eta \cdot 1_{\{i=\tau\}}-\frac{d \ln \left(f\left(\Delta t_{s s-1} ; \phi\right) / f\left(\Delta t_{s s} ; \phi\right)\right)}{d \ln \left(1+\tau_{t_{s s}}\right)} \\
& =\varepsilon_{i}^{c}-\frac{d \ln \left(f\left(\Delta t_{s s-1} ; \phi\right) / f\left(\Delta t_{s s} ; \phi\right)\right)}{d \ln \left(1+\tau_{t_{s s}}\right)}
\end{aligned}
$$

Hence, the additional sensitivity of spending relative to consumption is driven by the last term.

Elasticity Evaluating the derivatives of $f$ around $d \tau=0$ such that $d \ln f\left(\Delta t_{s s-1} ; \phi\right) \approx d \ln f\left(\Delta t_{s s} ; \phi\right)$ and using (11) we get

$$
\begin{aligned}
\frac{d \ln f\left(\Delta t_{s s-1} ; \phi\right)}{d \ln \left(1+\tau_{t_{s s}}\right)}-\frac{d \ln f\left(\Delta t_{s s} ; \phi\right)}{d \ln \left(1+\tau_{t_{s s}}\right)} & \approx \frac{e^{\phi \Delta t_{s s}}}{f\left(\Delta t_{s s} ; \phi\right)} \frac{d\left(\Delta t_{s s-1}-\Delta t_{s s}\right)}{d \ln \left(1+\tau_{t_{s s}}\right)} \\
& =\frac{e^{\phi \Delta t_{s s}}}{f\left(\Delta t_{s s} ; \phi\right)} \frac{B_{\tau}}{\delta+r} .
\end{aligned}
$$


Taking a first order approximation of $G(\phi) \equiv \frac{e^{\phi \Delta t}}{f(\Delta t ; \phi)}=\frac{\phi e^{\phi \Delta t}}{e^{\phi \Delta t}-1}$ around $\phi=0, G(\phi) \approx \frac{1}{\Delta t}+\frac{1}{2} \phi$, yields

$$
\frac{d \ln \left(f\left(\Delta t_{s s-1} ; \phi\right) / f\left(\Delta t_{s s} ; \phi\right)\right)}{d \ln \left(1+\tau_{t_{s s}}\right)} \approx \frac{B_{\tau}}{\delta+r}\left(\frac{1}{\Delta t_{s s}}+\frac{\phi}{2}\right)
$$

Evaluating $G$ at $\phi=0$ instead yields the approximation in (12).

Proof: Using de l'Hopital's rule, $G(0)=\lim _{\phi \rightarrow 0} G(\phi)=\frac{1}{\Delta t}$. After some algebra, the derivative of $G$ simplifies to $G^{\prime}(\phi)=\frac{e^{\phi \Delta t}\left(e^{\phi \Delta t}-1-\phi \Delta t\right)}{\left(e^{\phi \Delta t}-1\right)^{2}}$. Using de l'Hopital's rule again, $G^{\prime}(0)=\lim _{\phi \rightarrow 0} G^{\prime}(\phi)=$ $\frac{1}{2}$.

\section{B.2.4 Pre Tax Change Periods (until $t_{s s-1}$ )}

Consider the problem of choosing how to space $N$ trips planned to occur before the interim shopping trip at $t_{s s-1}=t_{\tau}^{-} \cdot{ }^{41}$ Without much loss of generality we start model time at a date that corresponds to a shopping transaction. The goal is to show that for an appropriate choice of tax change date $t_{\tau}$ there is a solution involving a constant trip interval $\Delta t=\Delta t_{s s-2}=\Delta t_{s s-q} \forall q \geq 2$ and constant beginning-of-period consumption $C=C_{t_{s s-2}}=C_{t_{s s-q}} \forall q \geq 2$. Define the start and end dates of the pre tax change period

$$
\begin{aligned}
t_{0} & =0 \\
t_{N} & =t_{\tau}^{-}=t_{s s-1} .
\end{aligned}
$$

There are $N+1$ transaction dates and $N$ transaction intervals. Also define $V\left(w_{t_{\tau}^{-}}\right)$as the value of the problem starting from the interim shopping trip at $t_{\tau}^{-}$given accumulated wealth $w_{t_{\tau}^{-}}$. The problem is

$$
V\left(w_{0}\right)=\max _{w_{t_{\tau}^{-}}, \Delta t_{0}, \ldots, \Delta t_{N-1}, C_{t_{0}}, \ldots, C_{t_{N-1}}} \sum_{k=0}^{N-1} e^{-\rho \sum_{j=0}^{k-1} \Delta t_{j}} U\left(C_{t_{k}}, \Delta t_{k}\right)+e^{-\rho t_{\tau}^{-}} V\left(w_{t_{\tau}^{-}}\right)
$$

subject to

$$
\begin{aligned}
& t_{\tau}^{-}=\sum_{k=0}^{N-1} \Delta t_{k} \\
& w_{0}=\sum_{k=0}^{N-1} e^{-r \sum_{j=0}^{k-1} \Delta t_{j}} K_{t_{k}}+e^{-r t_{\tau}^{-}} w_{t_{\tau}-}
\end{aligned}
$$

where the multiplier on first constraint is $\lambda_{1}$ and on second constraint is $\lambda_{2}$.

\footnotetext{
${ }^{41}$ Note that it is best for the household to take the interim trip as close to $t_{\tau}$ as possible, all else constant.
} 
Necessary condition for $\Delta t_{n}$

$$
e^{-\rho t_{n}} \lambda_{1}=\left[\partial_{\Delta} U_{t_{n}}^{\prime}-\rho \sum_{k=n+1}^{N-1} e^{-r \sum_{j=0}^{k-1} \Delta t_{j}} U_{t_{k}}\right]-\lambda_{2}\left[\partial_{\Delta} K_{t_{n}}^{\prime}-r \sum_{k=n+1}^{N-1} e^{-\rho \sum_{j=0}^{k-1} \Delta t_{j}} K_{t_{k}}\right]
$$

Necessary condition for $C_{t_{n}}$

$$
\partial_{C} U_{t_{n}}^{\prime}=\lambda_{2} \cdot \partial_{C} K_{t_{n}}^{\prime}
$$

Necessary condition for $w_{t_{\bar{\tau}}}$

$$
e^{-\rho t_{\tau}^{-}} V^{\prime}\left(w_{t_{\tau}^{-}}\right)=\lambda_{2} e^{-r t_{\tau}^{-}}
$$

Using (22) and $r=\rho$ we get

$$
\lambda_{2}=V^{\prime}\left(w_{t_{\tau}^{-}}\right)
$$

The consumption Euler equation is

$$
\frac{\partial_{C} U_{t_{n}}^{\prime}}{\partial_{C} U_{t_{n+1}}^{\prime}}=\frac{P_{t_{n}}}{P_{t_{n+1}}} \frac{f\left(\Delta t_{n} ; \phi\right)}{f\left(\Delta t_{n+1} ; \phi\right)} \frac{f\left(\Delta t_{n} ; \gamma\right)}{f\left(\Delta t_{n+1} ; \gamma\right)}
$$

The transaction Euler equation is obtained using (20),

$\partial_{\Delta} U_{t_{n}}^{\prime}-\rho e^{-\rho \Delta t_{n}} U_{t_{n+1}}^{\prime}-\left[\partial_{\Delta} K_{t_{n}}^{\prime}-r e^{-r \Delta t_{n}} K_{t_{n+1}}\right] V^{\prime}\left(w_{t_{\tau}^{-}}\right)=e^{-\rho \Delta t_{n}} \partial_{\Delta} U_{t_{n+1}}^{\prime}-e^{-r \Delta t_{n}} \partial_{\Delta} K_{t_{n+1}}^{\prime} V^{\prime}\left(w_{t_{\tau}^{-}}\right)$.

Using the constant guess for the solution, $\Delta t_{n}=\Delta_{t_{s s-2}}=\Delta t$ and $C_{t_{n}}=C_{t_{s s-2}}=C$, we obtain a condition similar to the steady state equation for the post tax transaction interval,

$$
\partial_{\Delta} U^{\prime}-\rho \frac{e^{-\rho \Delta t}}{1-e^{-\rho \Delta t}} U=\left[\partial_{\Delta} K^{\prime}-r \frac{e^{-r \Delta t}}{1-e^{-r \Delta t}} K\right] V^{\prime}\left(w_{t_{\tau}^{-}}\right) .
$$

Using similar steps as in the derivation of the steady state above, we can combine this relationship with (21) to yield

$$
(1-\sigma) \frac{\kappa}{P_{t_{s s-2}} S_{t_{s s-2}}}=e^{\phi \Delta t_{s s-2}} \frac{f\left(\Delta t_{s s-2} ; r\right)}{f\left(\Delta t_{s s-2} ; \phi\right)}-1 .
$$

Furthermore, since $V^{\prime}\left(w_{t_{\bar{\tau}}^{-}}\right)$is also the multiplier in the post-tax steady state, we can relate $C_{t_{s s-2}}$ and $C_{t_{s s}}$ through (21),

$$
\partial_{C} U_{t_{n}}^{\prime}=V^{\prime}\left(w_{t_{\tau}^{-}}\right) \partial_{C} K_{t_{n}}^{\prime}
$$

such that

$$
u^{\prime}\left(C_{t_{s s-2}}\right) f\left(\Delta t_{s s-2} ; \gamma\right)^{1 / \sigma-1} f\left(\Delta t_{s s-2} ; \phi\right)=V^{\prime}\left(w_{t_{\tau}^{-}}\right) P_{t_{s s-2}} \frac{f\left(\Delta t_{s s-2} ; \phi\right)}{f\left(\Delta t_{s s-2} ; \gamma\right)}
$$

which reduces to

$$
u^{\prime}\left(C_{t_{s s-2}}\right)=V^{\prime}\left(w_{t_{\tau}-}\right) P_{t_{s-2}} f\left(\Delta t_{s s-2} ; \gamma\right)^{-1 / \sigma}
$$


Hence,

$$
C_{t_{s s-2}}=\left(P_{t_{s s-2}} V^{\prime}\left(w_{t_{\tau}^{-}}\right)\right)^{-\sigma}
$$

and

$$
C_{t_{s s}}=\left(P_{t_{s s}} V^{\prime}\left(w_{t_{\tau}^{-}}\right)\right)^{-\sigma}
$$

such that

$$
\frac{C_{t_{s-2}}}{C_{t_{s s}}}=\left(\frac{P_{t_{s s-2}}}{P_{t_{s s}}}\right)^{-\sigma}
$$

If we use $S_{t_{s-2}}=C_{t_{s-2}} f\left(\Delta t_{s s-2} ; \phi\right)$ in (23), we have two equations in $\Delta t_{s s-2}$ and $C_{t_{s s-2}}$, which we solve to get the pre tax change solution

$$
\begin{aligned}
(1-\sigma) \frac{\kappa}{P_{t_{s s-2}} C_{t_{s-2}} f\left(\Delta t_{s s-2} ; \phi\right)} & =e^{\phi \Delta t_{s s-2}} \frac{f\left(\Delta t_{s s-2} ; r\right)}{f\left(\Delta t_{s s-2} ; \phi\right)}-1 \\
\frac{C_{t_{s s-2}}}{C_{t_{s s}}} & =\left(\frac{P_{t_{s s-2}}}{P_{t_{s s}}}\right)^{-\sigma}
\end{aligned}
$$

To make sure $\sum_{k=0}^{N-1} \Delta t_{k}=t_{\tau}$ is satisfied we set

$$
t_{\tau-}=N \cdot \Delta t_{s s-2}
$$

This solution has a straightforward interpretation: Intertemporal consumption allocation satisfies the standard consumption Euler equation (even in the presence of transaction fixed costs and product storability) and the optimal trip interval in the pre tax change period reflects the same trade-offs as in the final steady state. Figure 4 highlights these two features of optimal transaction intervals and spending and consumption plans.

\section{Tax Salience and Announcement Effects}

\section{C.1 Tax Salience: Evidence from Ballot Initiative}

A natural question that arises given the results displayed in Figure 2 is whether tax salience plays an additional role in consumers response to a sales tax rate chang and whether news about future sales tax changes prompt a response via an income or wealth effect. While the results in Section 4 document a significant degree of tax foresight on average, it seems reasonable that some households are not fully aware of the tax rate changes, or some aspects of the tax code such as the exemption status of certain goods is not fully salient (e.g., cookies vs. candies). In this section, we test whether more salient tax changes elicit larger spending responses. This analysis is motivated by several highly influential previous studies that document a large degree of nonsalience of sales tax rates among consumers (see the literature mentioned in the introduction). Table A.1 presents the results from this analysis.

Panel A uses two measures of tax salience and examines their impact on changes in household spending. The first is the aforementioned index of sales tax news coverage in the month prior to 
the change. Given that the size of the sales tax change strongly impacts the level of coverage, we first obtain the residuals from a regression of the amount of sales tax news coverage on the size of the change, the squared size of the change, and time fixed effects. With this approach, we interpret the resulting residuals as a measure of news coverage of the impending sales tax change that is unrelated to the size of the change (ideally driven by the amount of other important news in that period, editorial decisions, etc.). Here, the assumption is that the more that sales taxes are written about in local newspapers, the more likely it is that a given household will be aware of the upcoming change in sales taxes and that they will be in position to react to the change.

Columns 1 to 3 interact this news-based measure with changes in state sales taxes. To facilitate the quantitative interpretation, we normalize the news measure by its standard deviation. Since it is a residual, the resulting transformation has mean zero and a unit standard deviation (i.e., a standard score). We again find that, in general, sales tax changes have a negative relationship with spending in the month of the tax change, comparable with the baseline effects reported in Column 2 of Tables 1 and 4. Moreover, changes that had more news coverage (conditional on the size of the change) also had larger declines. The coefficient on the interaction term of Column 1 shows that an increase in news coverage of one standard deviation would increase the spending response to a 1 ppt sales tax change by about $20 \%$ (from $-1.8 \%$ to $-2.1 \%$ ). The effect is again similarly shared by taxable and tax-exempt spending.

Columns 4 to 6 take a different approach to testing heterogeneity in household responses across sales tax changes with different salience. Here we utilize data on state-level ballot measures that changed state sales taxes. Our prior is that sales tax changes enacted through state-wide ballots would garner more media attention than those enacted through a vote solely by their state representatives and also would force all voters to be at least somewhat aware of the initiative that they are voting on. Consistent with this hypothesis, we find that changes in sales tax rates that were authorized by a state-wide ballot measure tended to produce much larger responses among households.

\section{C.2 'News' Response: Income, Wealth and Substitution Effects}

Panel B of Table A.1 demonstrates some evidence for an announcement effect of sales taxes. For most of the changes in our sample, we are unable to determine when exactly the sales tax change was finalized (often 3 months to 12 months prior to the change taking place). For state ballot provisions, however, we can precisely measure this date, allowing us to look for changes in household spending behavior prior to the change actually taking place. ${ }^{42}$

In a model with fully informed and rational consumers, households would perceive this future tax increase as a persistent increase in future prices. At the time of the announcement (which is before time 0 in the model of Section 5), this leads to a spending response that is the combination

\footnotetext{
${ }^{42}$ Ideally we would weigh the responses by how close the outcome of the ballot proposition was in order to interpret the spending response as a rational response to a change in expected tax rates. Unfortunately, we do not yet have this data.
} 
of a negative income effect (the same pre-tax consumption plan is more expensive) and a positive intertemporal substitution effect (spending is temporarily cheaper in the period before the sales tax increase). In addition, there could be wealth effects that depend on the consumer's perception and valuation of what the government plans to do with the additional revenue.

Column 7 provides suggestive evidence that this effect might play a role, on average, across all ballots (whether they passed or failed), with the act of voting on the ballot being associated with a $0.5 \%$ decline in household retail spending. We further refine the analysis by separating these ballots into those that failed and those that passed, finding opposite signed coefficients. Judging the point estimates, we find a near zero effect on spending following a failed tax increase initiative, while we see a much larger decrease in spending following a successful tax increase vote. These results are consistent with forward-looking behavior on the part of consumer, although they are not statistically significant. 
Table A.1: Salience and Announcement Effects

A. Salience Effects

B. Announcement Effects

\begin{tabular}{|c|c|c|c|c|c|c|c|c|}
\hline \multirow{4}{*}{ Dependent variable: } & & \\
\hline & \multicolumn{3}{|c|}{ newspaper coverage } & \multicolumn{3}{|c|}{ ballot-induced tax changes } & \multirow{3}{*}{$\begin{array}{c}\Delta \ln (\text { total }) \\
\quad(7)\end{array}$} & \multirow{3}{*}{$\begin{array}{c}\Delta \ln (\text { total }) \\
(8)\end{array}$} \\
\hline & $\Delta \ln ($ total $)$ & $\Delta \ln ($ taxable $)$ & $\Delta \ln ($ exempt $)$ & $\Delta \ln ($ total $)$ & $\Delta \ln ($ taxable $)$ & $\Delta \ln ($ exempt $)$ & & \\
\hline & $(1)$ & $(2)$ & $(3)$ & $(4)$ & $(5)$ & (6) & & \\
\hline$\Delta \ln (1+$ sales tax rate $)$ & $\begin{array}{c}-1.738^{* * *} \\
(0.581)\end{array}$ & $\begin{array}{c}-2.124^{* *} \\
(1.053)\end{array}$ & $\begin{array}{c}-1.572^{* *} \\
(0.603)\end{array}$ & $\begin{array}{c}-1.526^{* *} \\
(0.687)\end{array}$ & $\begin{array}{l}-2.238^{*} \\
(1.179)\end{array}$ & $\begin{array}{c}-1.310^{* *} \\
(0.591)\end{array}$ & & \\
\hline $\begin{array}{l}\Delta \ln (1+\text { sales tax rate }) \\
\quad \times \text { Score }(\text { newspaper coverage })\end{array}$ & $\begin{array}{c}-0.361^{* * *} \\
(0.110)\end{array}$ & $\begin{array}{l}-0.336 \\
(0.257)\end{array}$ & $\begin{array}{c}-0.439^{* *} \\
(0.166)\end{array}$ & & & & & \\
\hline $\begin{array}{l}\Delta \ln (1+\text { sales tax rate }) \\
\quad \times \mathrm{I}(\text { state ballot proposition })\end{array}$ & & & & $\begin{array}{c}-4.195^{* * *} \\
(1.050)\end{array}$ & $\begin{array}{c}-4.765^{* *} \\
(2.038)\end{array}$ & $\begin{array}{c}-5.043^{* * *} \\
(0.889)\end{array}$ & & \\
\hline I(date tax rate change proposed) & & & & & & & $\begin{array}{l}-0.529 \\
(0.330)\end{array}$ & $\begin{array}{l}-1.706 \\
(1.444)\end{array}$ \\
\hline $\begin{array}{l}\mathrm{I} \text { (date tax rate change proposed }) \\
\quad \times \mathrm{I} \text { (ballot proposition failed })\end{array}$ & & & & & & & & $\begin{array}{c}1.434 \\
(1.493)\end{array}$ \\
\hline $\begin{array}{l}\text { Score(newspaper coverage } \\
\quad \text { of state sales tax changes) }\end{array}$ & $\begin{array}{l}-0.001 \\
(0.001)\end{array}$ & $\begin{array}{l}-0.001^{*} \\
(0.001)\end{array}$ & $\begin{array}{c}0.001 \\
(0.001)\end{array}$ & & & & & \\
\hline I(date ballot proposition failed) & & & & $\begin{array}{c}0.022^{* * *} \\
(0.005)\end{array}$ & $\begin{array}{c}0.030^{* * *} \\
(0.009)\end{array}$ & $\begin{array}{c}0.022^{* * *} \\
(0.005)\end{array}$ & & \\
\hline I(ballot proposition failed) & & & & & & & & $\begin{array}{l}-0.002 \\
(0.006)\end{array}$ \\
\hline Period FE & Yes & Yes & Yes & Yes & Yes & Yes & Yes & Yes \\
\hline Household FE & Yes & Yes & Yes & Yes & Yes & Yes & Yes & Yes \\
\hline Observations & $5,822,806$ & $5,777,878$ & $5,865,177$ & $5,865,949$ & $5,928,421$ & $5,777,966$ & $5,860,476$ & $5,860,476$ \\
\hline R-squared & 0.016 & 0.015 & 0.014 & 0.014 & 0.012 & 0.013 & 0.014 & 0.014 \\
\hline
\end{tabular}

Notes: The dependent variables are monthly changes in logged household spending as measured by Nielsen Consumer Panel data. Taxability and tax-exemption status of household spending is defined at a state level depending on what categories of goods are exempt from sales taxes (e.g., groceries, clothing, medication). Columns 1-3 interact changes in state sales tax rates with the level of newspaper coverage (measured as the demeaned ratio of articles mentioning sales taxes to the total number of articles in newspapers within the state covered by Access World News, normalized by its standard deviation). Columns 4-6 interact changes in sales tax rates with an indicator for whether the change in state sales tax rates was driven by a ballot measure (as opposed to being enacted by the legislature). Columns 7 and 8 use, as independent variables, indicators for dates when ballot initiatives that would change state sales tax rates were voted on (as opposed to the dates they were enacted). Column 8 interacts these indicators with another indicator that signifies the ballot not being successfully passed (and thus resulting in no change in sales tax rates). For robustness, the dependent variables are winsorized at the 1\% level. Regressions span years 2004-2014. Robust standard errors in parentheses adjust for arbitrary within-household correlations and heteroskedasticity and are clustered at the state level. 